\title{
LA SOSPECHA DE INGLESES EN EL EXTREMO SUR DE CHILE, 1669-1683: ACTITUDES IMPERIALES Y LOCALES COMO CONSECUENCIA DE LA EXPEDICIÓN DE JOHN NARBOROUGH
}

MARÍA XIMENA URBINA C. ${ }^{a}$

\section{RESUMEN}

Con documentación principalmente del Archivo Nacional de Santiago, Chile, y del Archivo General de Indias, Sevilla, para analizar las repercusiones de la expedición de John Narborough a Chile, en 1670 , se pretende en este artículo contribuir a la comprensión del proceso en que, durante el período colonial, la presencia inglesa en las costas del océano Pacífico Sur, o la amenaza de ella, generó distintas reacciones geopolíticas a nivel local (del gobernador de Valdivia y del de Chiloé), regional (del gobernador Chile y del virrey del Perú), e imperial (las reacciones de la corte en Madrid y las del embajador de España en Londres). Es importante el análisis en conjunto porque las actitudes que generaron los avisos externos (advertibles en las opiniones de la correspondencia entre autoridades) y las reacciones ante ellos (visibles en los hechos empíricos que constan en la documentación), son una ocasión para conocer los comportamientos diferenciados del imperio español en su centro y en sus periferias, que son, a su vez, producto de distintas interpretaciones de los hechos o noticias, de acuerdo a los diferentes intereses. Se trata de una coyuntura geopolítica ocurrida en un lugar remoto de los centros económicos indianos, que permite al historiador aproximarse a las maneras de representar y comprender los territorios en el siglo XVII.

PALABRAS CLAVES: John Narborough, estrecho de Magallanes, Chiloé, Inglaterra.

\section{SUSPICION OF ENGLISH AT THE SOUTHERN END OF CHILE, 1669-1683: IMPERIAL AND LOCAL ATTITUDES AS A RESULT OF JOHN NARBOROUGH'S EXPEDITION}

\footnotetext{
ABSTRACT

Using documents mainly from the Archivo Nacional de Santiago, Chile, and the Archivo General de Indias, Seville, to analyze the impact of the expedition of John Narborough to Chile in 1670, this article aims to contribute to the understanding of the process by which, during the colonial period, the

a Profesora del Instituto de Historia, Pontificia Universidad Católica de Valparaíso, maria.urbina@pucv.cl. Grupo de Estudios "Circulación de la información, objetos y personas". Este artículo es producto del proyecto Fondecyt Regular 2015, "Dimensión local de los conflictos imperiales entre España e Inglaterra en el período colonial: la Patagonia Occidental”, N 1150852, del que soy la Investigadora Responsable.
} 
British presence in the South Pacific coast, or the threat of it, generated different types of geopolitical reactions. First in a local level (those from the governor of Valdivia and Chiloe), then in a regional level (the governor of Chile and the viceroy of Peru) and finally in an imperial level (the reactions of the court in Madrid and Spain's ambassador in London). It is important to analyze this documents as a whole, as the attitudes that generated external warnings (advertibles in the opinions in the letters between authorities) and the reactions to them (visible in empirical facts in the documentation), are an opportunity to learn about differentiated behaviors from the Spanish empire in its center and its periphery, which are, in turn, due to different interpretations of the facts or news, according to different interests. This is a geopolitical situation that occurred in a remote part of the Indians economic centers, allowing the historian to approach the different ways of representing and understanding the territories in the seventeenth century.

KEY WORDS: John Narborough, Strait of Magellan, Chiloé, England.

\section{INTRODUCCIÓN}

De vez en cuando llegaban desde Londres a la corte española noticias de estar los ingleses preparando ataques al Mar del Sur, o en específico a Chile, que era considerado el valioso antemural del Perú. Estos avisos fueron comunes desde mediados del siglo XVII en adelante, cuando Inglaterra tomó una actitud más ofensiva respecto de los territorios indianos ${ }^{1}$. Les interesaba hostilizar a los españoles, hacerse de los metales preciosos americanos e introducir el comercio, que les era vedado. Excepto la plaza fuerte de Valdivia (refundada en 1645) y la provincia de Chiloé (cuyos habitantes indígenas no se habían unido a la gran rebelión mapuche-huilliche iniciada en 1598), todo el territorio entre el río Bío Bío, por el norte, y el confín del continente, por el sur, no tenía presencia alguna española y estaba poblado por grupos indígenas no sujetos a la Corona, y como tales, según interpretaban los extranjeros, convertibles en aliados suyos ${ }^{1}$. Por lo tanto, el territorio era vulnerable a la ocupación de los enemigos de la corona, quienes no veían impedimento legal alguno en tomar posesión y establecerse en territorios que no lo estaban efectivamente por otros reinos. Para la fecha que nos ocupa, los ingleses ya habían

1 El más exhaustivo recuento cronológico de las expediciones inglesas al océano Pacifico sur puede verse en Martinic, M. (1992). Historia de la Región Magallánica. Punta Arenas, Chile: Universidad de Magallanes, Vol. 1, capítulos 3 al 6. También, del mismo autor, (1977). Historia del estrecho de Magallanes. Santiago, Chile: Andrés Bello.

2 León, L. (2001). Indios, piratas y corsarios en las costas de Araucanía y Patagonia, 1557-1790. Boletín de Historia y Geografía, 15, 117-151. tenido ocasión de ejecutar estos actos, arrebatando a España territorios en las Indias, además de practicar el comercio, el saqueo y la piratería.

Aun así, casi todos los avisos eran amenazas no concretadas, porque no todos los barcos que se aprontaban para salir de la ría de Londres tenían fines punitivos en las costas sudamericanas del Pacífico. A estos proyectos tanto holandeses (de la primera mitad del siglo $\mathrm{XVII}^{3}$ ) como ingleses (del mismo siglo y el siguiente), Gabriel Guarda les llamó planes de ataque, y destacó en su libro Flandes Indiano, cómo ellos dinamizaron la defensa de Chile contra el enemigo externo 4 . Los planes de ataque, avisos o papeles llegados a la corte de parte de sus informantes en Londres, se traducían en alertas al virrey del Perú y al gobernador de Chile, y ello activaba, en niveles de distinta envergadura, la defensa de las costas y la vigilancia o exploraciones acerca de los extensos y desconocidos litorales desde Chiloé hasta el confín del continente. Son precisamente estos papeles de Londres y el temor al enemigo inglés, el centro de las relaciones que pretendo establecer en este artículo, hilando información escrita (correspondencia) y mapas, que no se habían relacionado entre sí, para, por un lado, comprender la circulación de la información en el imperio español, y entre España

3 Vázquez de Acuña, I. (1992). Las incursiones corsarias holandesas en Chiloé: Simón de Cordes (1600) y Enrique Brouwer (1643). Santiago, Chile: Universitaria. Stewart, H. (2000). Del Mar del Norte al Mar del Sur. Navegantes británicos y holandeses en el Pacífico suroriental, 15701807. Valparaíso, Chile: Universidad de Playa Ancha.

4 Guarda, G. (1990). Flandes Indiano. Las fortificaciones del Reino de Chile, 1541-1826. Santiago, Chile: Universidad Católica de Chile, capítulos 2 al 12. 
e Inglaterra; y por otro, el proceso en que nacen o se modifican las representaciones, en este caso, de un territorio. Estos documentos son principalmente de los Fondos Morla Vicuña ${ }^{5}$ y Capitanía General ${ }^{6}$, del Archivo Nacional de Santiago, Chile; de los Manuscritos Medina, existentes en la Sala Medina de la Biblioteca Nacional de Santiago; y del Archivo General de Indias, Sevilla. He tomado como coyuntura la llegada a la plaza fuerte de Valdivia de una expedición inglesa, en diciembre de 1670, para estudiar cómo sus consecuencias geopolíticas -el temor a una nueva llegada del inglés- se proyectaron por más de diez años, potenciadas por las noticias surgidas desde el ámbito local, en Chiloé. No me referiré, por lo tanto, a los planes de defensa que generó la expedición, por haberlo estudiado ya Gabriel Guarda7. Tanto como en lo publicado por Guarda y Martinic, se funda este estudio en uno de los libros de Vázquez de Acuña8.

\section{ANTECEDENTES O PROYECTOS INGLESES INMEDIATOS, 1655-1669}

Después de la travesía de Francis Drake (1578), secundada por la de Thomas Cavendish (1586-1588), hubo varios otros intentos de cruces interoceánicos. Como no fueron exitosos -salvo el último de ellos, de Richard Hawkins (1594)-, el interés inglés decayó y no hubo más navegaciones sino hasta la que se trata aquí.

Todo se reactivó a mediados del siglo XVII.

5 El fondo Morla Vicuña, del Archivo Nacional de Santiago, Chile, contiene copias manuscritas hechas a fines del siglo XIX de documentos españoles del Archivo General de Indias, del Archivo de Simancas, y del Depósito Hidrográfico de la Armada (hoy, Archivo del Museo Naval de Madrid) que contenían información relevante para estudiar la historia de los límites de australes Chile. Los documentos recopilados por este ex canciller y diplomático dieron origen a un libro, publicado póstumamente. Morla, C. (1903). Estudios histórico sobre el descubrimiento y conquista de la Patagonia y de la Tierra del Fuego. Leipizg, Alemania: F.A. Brockhaus.

6 Aunque Guarda refiere que también contiene documentación relativa a este tema el volumen 716 de Capitanía General, lamentablemente éste ya no existe, ni en original ni en microfichas.

7 Guarda 1990, op. cit., pp. 16-18. El mismo autor, (2001). Nueva Historia de Valdivia. Santiago, Chile: Universidad Católica de Chile, p. 184, concluyó que la reacción que generó la expedición de Narborough se tradujo en nuevos planes de defensa en Valdivia: si la ocupación holandesa había provocado la repoblación y fortificación, la expedi-
Inglaterra era una amenaza real para España, y esto no excluía al territorio de la gobernación de Chile. En 1655 Simón de Cáceres -judío sefardita nacido en Ámsterdam y residente en Inglaterrapresentó al lord protector, Oliver Cromwell, un proyecto relativo al sur de Chile. El plan era comercial y proponía que Inglaterra, con cuatro fragatas y cuatro naves de abastecimiento, tomara la ciudad de Valdivia, de la que, decía, los indígenas habían expulsado a los españoles hacía mucho tiempo, y en cuyo territorio había oro. Se utilizaría la isla de la Mocha (como lo había hecho Drake antes) como buen escondite y punto de reunión para sus barcos, para apoyar el proyectado establecimiento en Valdivia. El objetivo último era aliarse con los indígenas locales para apoderarse del Mar del Sur, y así capturar tanto el tesoro que se conducía a Panamá, como el que iba desde Filipinas a Acapulco a bordo del galeón de Manila. Éste fue concebido por Cáceres como complementario al que se haría por el Mar del Norte, atacando la flota del Caribe ${ }^{9}$.

Este proyecto no se concretó, pero ese mismo año los ingleses se apoderaron de Jamaica, y con ello garantizaron su presencia permanente en el mar Caribe. Fue un logro del western design, como lo llama Julio Albi ${ }^{10}$. Cinco años más tarde el rey comunicó a las autoridades de las Indias la cesación de armas con Inglaterra ${ }^{11}$, ordenando que ello se interprete como paz, y se actúe según las paces de 1604 con Inglaterra, ratificadas en 1630 , en las que se había manifestado que ingleses

ción que tratamos la consolidó.

8 Vázquez de Acuña, I. (2004). Historia naval del reino de Chile, 1520-1826. Valparaíso, Chile: Compañia Sudamericana de Vapores.

9 Böhm, G. (1980). Simon de Casseres y su plan de conquista de Chile: antecedentes históricos. Ibero-Amerikanisches Archiv, Neue Floge, 6(1), 117-147. Böhm en su artículo reproduce en castellano el proyecto, que cita de Bodleian Library, Oxford, Rawlinson MSS, A 30, fol. 151-152. p. 144. El proyecto y el haberse enterado la corte de él, lo refiere Barros, J. (1988). La expedición de Narborough a Chile: nuevos antecedentes. Anales del Instituto de la Patagonia, Serie Ciencias Sociales, 18, 35-59, p. 40. También Guarda 1990, op. cit., p. 9, quien cita a BN, SM, MM, 179, fjs. 32 y 88

10 Albi, J. (1987). La defensa de las Indias (1764-1799). Madrid, España: Instituto de Cooperación Americana, p. 25.

11 Cédula del rey al presidente de la Audiencia de Chile, Madrid, 13 de septiembre de 1660. Archivo Nacional Histórico (Santiago, Chile), Fondo Capitanía General, Volumen 715 (en adelante ANH, CG, 715), fjs. 67 y 67v. 
y españoles sean bien tratados en los puertos de la otra corona en los casos de arribadas lícitas y no de otra manera ${ }^{12}$. España permitía a Inglaterra las arribadas, pero prevenía a las autoridades indianas que velen mucho sobre que los ingleses (tomando por pretexto estas arribadas) no pasen de usar de ellas para introducir el comercio, que les está tan prohibido por los graves inconvenientes $y$ daños que resultarian ${ }^{13}$. Esta advertencia la puso en práctica el gobernador de Valdivia, cuando resolvió apresar a algunos ingleses del barco de Narborough, como ya se verá. A pesar de la paz oficial de 1660, desde Jamaica los ingleses continuaron organizando operaciones contra los dominios de la Corona, en medio, también, de la guerra entre holandeses $e$ ingleses en el Caribe (1665 a 1667) ${ }^{14}$.

Se redactó, asimismo, un proyecto sin firma ni fecha, pero que Gabriel Guarda resumió y dató por los mismos años que el de Cáceres, que propuso que ocho fragatas doblasen el estrecho de Magallanes, tomasen las islas Mocha y Santa María, capturasen el tesoro en su tránsito del Callao a Panamá, e instalasen un establecimiento en Valdivia. Como el de Cáceres, este también era un plan tenaza, para estrangular el imperio por Panamá, porque se complementaría con ataques desde el Caribe ${ }^{15}$. Sabemos también, por el mismo Guarda, que en septiembre de 1662 llegó a manos de Felipe IV un proyecto de cruce por el estrecho de Magallanes o el de Le Maire, que incluía la ocupación de Valdivia y de las islas de las Perlas para apoderarse del tesoro ${ }^{16}$. Enterada de estos planes, la corona española iba alertando a las autoridades indianas, como lo dijo el virrey del Perú en 1675: que desde hace diez años se recibían repetidas cédulas, sobre que los enemigos de Europa tratan de pasar con armada a infestar

12 Cédula del rey al presidente de la Audiencia de Chile, Madrid, 25 de septiembre de 1660. ANH, CG, 715, fjs. 71 y $71 v$.

13 Cédula del rey al presidente de la Audiencia de Chile. Madrid, 13 de septiembre de 1660. ANH, CG, 715, fjs. 68 y $68 \mathrm{v}$.

14 Albi 1987, op. cit., p. 26.

15 Guarda 1990, op. cit., p. 9. El expediente, considerado en su momento por la Junta de Guerra de Indias, se titula "Traducción en español del papel que se presentó al Consejo Privado, facilitando la sorpresa y fortificación de algunos puertos de América, con carta de Alonso Rancaño, esta Mar del Sur y hacer hostilidades en estas costas y puertos ${ }^{17}$.

\section{LA SWEEPSTAKES, COMANDADA POR JOHN NARBOROUGH, EN VALDIVIA, 1670}

\section{a. Carlos Enríquez y John Narborough}

La expedición de Narborough, que zarpó del puerto de Downs, Inglaterra, el 6 de octubre de 1669 según el calendario gregoriano, iba a sondear posibilidades de instalar en el futuro un asentamiento británico en el estrecho de Magallanes o en sus cercanías, y de practicar el comercio con indígenas no sujetos a la corona española, entre el Estrecho y Valdivia. Eran dos barcos: la fragata Sweepstakes, de 300 toneladas, 36 cañones y 80 hombres, al mando del capitán John Narborough, y el pingüe Batchelour, de 70 toneladas, con el capitán Humphrey Fleming. Este último regresó a Inglaterra luego de una tormenta, antes de tocar América, y supuso a la capitana perdida. La Sweepstakes, que iba en busca de puerto Deseado, permaneció un mes allí, y luego se trasladó al de San Julián, lugar de encuentro acordado en caso de separarse las naves. Después de retroceder a puerto Deseado para abastecerse de focas y pingüinos, y habiendo ya pasado un año desde su zarpe en Inglaterra, cruzó el estrecho de Magallanes sin mayores inconvenientes, y puso el rumbo hacia Valdivia. En el camino recalaron en la isla Nuestra Señora del Socorro (hoy Guamblín), el 6 de diciembre de 1670, mientras que el día 15 avistaron la isla de Chiloé, pero no bajaron a tierra. El 24 de diciembre llegaron a la entrada fluvial que conducía a Valdivia, y el 26 un bote fue a tierra, encontrándose con españoles de uno de los fuertes. El encuentro fue cordial -los ingleses

de 24 de mayo". Guarda lo refiere de Biblioteca Nacional (Santiago, Chile), Sala Medina, Manuscritos Medina, Tomo 173 (en adelante BN, SM, MM, 173), f. 237.

16 Guarda 1990, op. cit., p. 9, citando a BN, SM, MM, 182, f. 67. También informa que el recibimiento de este aviso real en la Audiencia de Chile coincidió con el llegado desde Valdivia, en octubre de 1663, de haberse visto velas enemigas en ese puerto.

17 El virrey del Perú al rey, Lima, 28 de abril de 1675. Archivo General de Indias (Sevilla, España), Audiencia de Chile, Legajo 23 (en adelante AGI, Chile, 23), R.3, N. 83. 
dijeron que iban rumbo a China-, e invitaron a los españoles a su barco. Subieron cuatro, y al día siguiente, aprovechando la ocasión de devolver a tierra a sus invitados, pudieron observar que la plata abundaba en Valdivia, tal como los españoles les hicieron creer. El 28 los españoles retuvieron a otro grupo de ingleses que había bajado a hacer aguada, y se informó a Narborough que solo serían devueltos si la Sweepstakes entraba en la bahía y se ponía bajo el fuego los cañones de los fuertes. El capitán no aceptó la condición y no consiguió que se le devolviera a sus cuatro hombres, y el 31 de diciembre puso rumbo al sur. Luego de reconocer el Estrecho buscando, como en el viaje de ida, oro, llegó a Inglaterra el 23 de junio de $1671^{18}$.

En la historiografía chilena, el episodio fue narrado por Barros Arana y por Vicuña Mackenna, en la segunda mitad del siglo $\mathrm{XIX}^{19}$, de acuerdo al diario del viaje del capitán John Narborough, publicado en $1694^{20}$. Desde entonces no hubo más investigación sobre esta expedición y solo un siglo más tarde se le volvió a considerar, cuando Mateo Martinic y David Moore publicaron en esta misma revista (Anales del Instituto de la Patagonia, Serie Ciencias Sociales, hoy Magallania), en 1982, un estudio sobre uno de los mapas producidos por Narborough, considerando también sus

18 Barros 1988, op. cit. pp. 36-38. Las fuentes inglesas que se conocen de este viaje son las referidas en la cita número 21. A estas habría que agregar los documentos de archivo que dio a conocer Barros y señaló en el artículo citado, y que son: un resumen del viaje ("A voyage of the Sweepstakes to the Straits of Magellan..."), de la autoría de alguien llamado Richard Williams, que viajó en la Sweepstakes, fechado el 13 de junio de 1671, existente en la Royal Society, Londres; otro es "Part of Sir John Narborough's account of his voyage to the Straits of Magellan, 13 oct. 1669-9 Jan 1670/1", en Bodleian Library, Rawlinson Manuscripts A. 318; y por último, tres documentos firmados por Carlos Enríquez, siendo dos de ellos proyectos suyos recibidos por el rey de Inglaterra, para realizar la empresa que capitaneó Narborough, y que están, en la Public Record Office, Vol. C.O. 1/33 (The National Archives).

19 Vicuña, B. (1869). Historia de Valparaíso, crónica politica, comercial y pintoresca de su ciudad y de su puerto, desde su descubrimiento hasta nuestros días, 1536-1868. Valparaíso, Chile: Imprenta de Albion de Cox y Taylor, pp. 231-241. Barros, D. (1932). Historia general de Chile. Santiago, Chile: Nascimento. Tomo V, 141-152. La primera edición es de 1884. descripciones sobre el Estrecho como la más importante contribución a su conocimiento en materia de náutica, geografía, botánica y etnografía, hasta entonces. Esta información hay que entenderla en el contexto del interés por tener un conocimiento geográfico afinado de los escenarios de América, y de los recursos naturales y logísticos disponibles, en caso de tener que ocuparlos. Martinic y Moore no omitieron referirse a las conexiones del viaje con hechos locales, anunciando cómo el viaje de Narborough a las costas chilenas acarreó inesperadas consecuencias ${ }^{21}$. En la misma década el historiador José Miguel Barros encontró en Londres información que le permitió saber los motivos del viaje, y redactó un artículo para la misma revista en $1988^{22}$. Antes de publicar su trabajo, compartió con Gabriel Guarda sus documentos y el manuscrito que tenía preparado sobre el tema, para enriquecer con ellos el Flandes Indiano, que Guarda estaba redactando. Luego, lo incorporó también Mateo Martinic en su libro de $1992^{23}$. Sorprende, así, que no haya habido más estudios sobre este viaje y sus consecuencias en Chile, a pesar que, como notó Guarda, la documentación generada en España, Perú y Chile sobre esta expedición es desbordante; materia para una vasta

20 El diario que John Narborough llevó de este viaje fue publicado solo en 1694, en forma abreviada en un libro que compilaba otros diarios de diferentes viajes: VV.AA (1694). An account of several late voyages and discoveries to the south and north. Towards the streights of Magellan, the South Seas, the vast tracts of land beyond Hollandia Nova, also towards Nova Zembla, Greenland or Engrondland, by Sir John Narborough, capitan Jasmen Tasman, capitan John Wood, and Frederick Marten of Hamburgh. Londres, Inglatera: Printed for Sam. Smith and Benj. Walford, printers to the Royal Society, at the Prince's Arms, in S. Paul's Churchyard. Se conoce sobre esta expedición otro diario, el de John Wood, publicado dentro del libro A collection of original voyages..., London, Printed for James Knapton, 1699, con el título de "Capt. Wood's voyage thro' the streights of Magellan".

21 Martinic, M., \& Moore, D. (1982). Las exploraciones inglesas en el estrecho de Magallanes 1670-1671. El mapa manuscrito de John Narborough. Anales del Instituto de la Patagonia, Serie Ciencias Humanas, 13, 7-20.

22 Barros 1988, op. cit.

23 Guarda 1990, op. cit., pp. 16-18. Martinic 1992, op. cit., Tomo 1, pp. 240-243. 
monografía ${ }^{24}$. La historiografía inglesa, por supuesto, considera este viaje en la secuencia general de sus antiguas acciones en el Pacífico Sur en busca de riquezas minerales y comercio, sin ocuparse de sus efectos en Chile y Perú ${ }^{25}$.

Barros probó que el viaje tuvo su origen en un personaje llamado Carlos Enríquez - ¿español? residente en Inglaterra-, quien en 1669 presentó dos proyectos al rey Carlos II, y que fue el real jefe de la expedición, y no el capitán Narborough ${ }^{26}$. Un proyecto era para descubrir las costas y pasos del estrecho de Magallanes, pero éste no se conoce sino solo por referencia. El otro proyecto, fechado en Londres a 14 de julio de 1699, era para establecer una colonia en el Estrecho, en la isla -dice- que los españoles llaman Santa Clara y poblarla con 200 personas de distintas profesiones y oficios, de las que él, Enríquez, sería la máxima autoridad. Con esta base, dice, esperaba reducir "en breve las Indias o la mayor parte" de ella a la obediencia del rey de Inglaterra, y abrir Buenos Aires, Portobelo y Panamá al comercio británico. En una tercera propuesta, de 25 de julio, se extiende sobre lo ya planteado y reitera que son dos

24 Guarda 2001, op. cit., p. 184.

25 Entre otros, Williams, G. (1973). "The inexhaustible fountain of gold": English proyects and ventures in the South Seas, 1670-1750. En J. Flint y Williams, G. (Eds.), Perspectives of Empire (pp. 27-53). Londres, Inglaterra: Longman Group Limited. Dyer, F. (1931). The life of admiral Sir John Narbrough. "The great commander and able seaman". Londres, Inglaterra: P. Allan. Entre otros, Williams, G. (1973). "The inexhaustible fountain of gold": English proyects and ventures in the South Seas, 1670-1750. En J. Flint y Williams, G. (Eds.), Perspectives of Empire (pp. 27-53). Londres, Inglaterra: Longman Group Limited. Dyer, F. (1931). The life of admiral Sir John Narbrough. "The great commander and able seaman". Londres, Inglaterra: P. Allan.

26 En un artículo de 1980, Böhm advirtió que el viaje fue ideado por el cripto-judío Enríquez, el organizador y jefe, y que logró convencer a Carlos II de Inglaterra que diera su apoyo y financiamiento (véase cita $N^{\circ} 10$ ). En 1986 lo afirmó también Peter Bradley, e hizo un brillante análisis de las que podrían ser las reales motivaciones de Enríquez. Bradley, P. (1986). Narborough`s Don Carlos. The Mariner's Mirror, 72 (4), 465-475. Con toda seguridad, al momento de preparar la investigación, Barros no conocía ni el artículo de Böhm ni el de Bradley. Este Carlos firmaba en Inglaterra como Don Carlos Enríques, y era conocido como español. En el Sweepstakes le llamaban Don Carlos, y una vez apresado en Valdivia, decía llamarse Carlos Henríquez Clerque. En la docu- las opciones: una, que se le permita ir a explorar el Estrecho, y la otra, más costosa, ir a colonizarlo ${ }^{27}$. Al parecer (porque no están las instrucciones reservadas) el proyecto aprobado por el rey fue el exploratorio y comercial. Quizá, también, la expedición era el primer paso para establecer el otro proyecto. Al menos así lo hizo saber Carlos Enríquez a las autoridades españolas, después de que en Valdivia desembarcase solo y con motivos desconocidos (bajó a tierra antes que los cuatro que fueron a hacer aguada), cargado de objetos para intercambiar con los indígenas, y fuese enviado a entrevistarse con el gobernador de Chile y a Lima, siendo interrogado varias veces entre 1671 y 1682 , junto con los otros cuatro ingleses ${ }^{28}$, porque, como en 1655 los ingleses se habían apoderado de Jamaica; como se habían visto en varias ocasiones velas sospechosas; y como había repetidas cédulas avisando de sus posibles arribadas, el gobernador de Valdivia no creyó que fueran camino a China. En eso no se equivocó.

En sus primeras declaraciones, las más verosímiles $^{29}$, dijo Enríquez que el objetivo intermedio era comerciar con indígenas, pero que el objetivo

mentación se escribe Enriques, Enriquez o Henriques, pero lo he uniformado como Enríquez. En sus sucesivas declaraciones daba identidades y nacionalidades distintas, además de diferentes versiones sobre los motivos de haber venido a Chile. Juan Gil lo calificó como redomado farsante, Gil, J. (1989). Mitos y utopías del Descubrimiento, Tomo 2, El Pacífico. Madrid, España: Alianza, p. 296, y Sergio Villalobos, como mentiroso con infulas, Villalobos, S. (1999). Historia del pueblo chileno. Santiago, Chile: Universitaria, p. 131. Es un verdadero personaje, tanto como para escribir una fas cinante novela, como lo notó Guarda 1990, op. cit., p. 18.

En realidad, fue Francisco de Seyxas y Lovera, en 1693, quien primero ponderó la importancia del viaje y de Henríquez dentro de él. Seyxas y Lovera, Francisco, Piratas y contrabandistas de ambas Indias y estado presente de ellas (1693), Edición, anotación y estudio preliminar de Clayton Mc Carl (2011). La Coruña, España: Fundación Barrié, pp. 145-149.

27 Barros, 1988, op. cit., p. 43.

28 Estos eran Thomas Armiger, de 40 años, nacido en Norfolk; John Fortescue, de 27 años, nacido en Kent, que había sido capitán y era cosmógrafo y matemático, quien anda marcando todos estos puertos; Hugh Coe y Tomás de la Iglesia, un mulato libre de 34 años, criado de Enríquez, natural de Sanlúcar de Barrameda, católico, y quien por haberse ido a Inglaterra a los 14 años, sabía también hablar inglés, por lo que actuó de intérprete. 
final era establecer una base inglesa que permitiese el comercio con las Indias Orientales por la vía occidental, y además, apoderarse de toda la América española, que es lo que se ve en sus proyectos. Entre lo que Enríquez informó al gobernador de Chile, primero, y al virrey del Perú, después, destaca el haber dicho que Inglaterra tenía un plan de ocupación de América, desde el Mar del Sur, comenzado por Valdivia y enlazado con el flanco de Jamaica; que se empeñaba Inglaterra en encontrar el estrecho de Anian, que esperaba comunicase el Pacífico con el Atlántico por el extremo norte de América (como el de Magallanes lo hacía por el sur); que se buscaba poblar y fortificar Magallanes para asegurar y acortar los viajes hacia el Oriente; y que la parte interesada que había conseguido autorización del rey era la Compañía Real del Comercio de Inglaterra, invirtiendo en esa y las siguientes exploraciones dos millones de libras esterlinas, sin las cantidades que los reyes de Suecia y Dinamarca tienen ofrecidas como interesados en dicha compañía, para cuyo efecto enviaron dichos príncipes sus embajadores a Londres el año 1669 para ajustar el negocio para disponer los preparativos necesarios que se habian de conducir a los puertos que se hubiesen de poblar según las noticias e informes que de este viaje adquiriese $e^{30}$. Nada de esto, por cierto, se dice en los proyectos que presentó en 1669 al rey de Inglaterra. En ellos no se menciona el respaldo de ninguna Compañía, y el plan aparece como fruto de su propia inventiva y la experiencia que dice tener en las Indias. Sin embargo, no podemos descartar que la idea de Enríquez haya coincidido con intereses precedentes.

29 Las primeras declaraciones escritas, las de Chile, son la carta de Enríquez al presidente de Chile, de 16 de enero de 1671. BN, SM, MM, 161, Dcto. 3218; otra al virrey del Perú, Valdivia, 27 de enero de 1671. British Library, Add. Ms. 21.539, Spanish American Papers, Melfort Papers; otra al rey, de Concepción, 11 de febrero de 1671. BN, SM, MM, 161, Dcto. 3219; y las declaraciones hechas el 12 de marzo de 1671 en Valparaíso ante Francisco de Cárdenas, fiscal de la Audiencia, para hacer las averiguaciones que le parecieren convenientes en orden a las causas, motivos y designios en que han venido a estas costas. Le interesaba al presidente de Chile, por la poca seguridad que se tiene que el bajel en que vinieron los dichos ingleses haya desembocado el Estrecho, y los accidentes que se pueden ofrecer en la mar, y ser muy contingente encontrarlo y malograrse las noticias que dichos ingleses puedan dar tocantes al real servicio, conservación y seguridad de estos reinos, y que en éste se sepan anticipadamente. BN, SM, MM, 161, Dcto. 3221.
¿Cuál era la percepción inglesa del confín austral en esa época? ${ }^{31}$. No sabemos cómo evaluó Carlos II las noticias adquiridas por Narborough y sus hombres, ni porqué no hubo una segunda expedición: ¿fue porque el promotor del viaje (Enríquez) ya no estaba; porque después otras fueron las prioridades; o porque lo efectivamente explorado ya no se consideraba tan atractivo como para colonia o comercio?

Declaró Enríquez que fue nombrado director general, con la instrucción de reconocer toda la costa desde el cabo San Antonio hasta el estrecho de Magallanes, y desde allí hasta Valdivia, y que viese $y$ reconociese los fuertes y los sondease para ver dónde se podía poblar, y que marcase las tierras y reconociese los moradores y climas de ellas, y que tratase de comunicarlos y solicitarlos asi con dádivas como con agasajos ofreciéndoles de su parte todo agasajo y favor. Se le instruyó, además, que no hiciesen daño a los españoles ni a cosas que les pertenecian, sino que traten y contraten llanamente. Preguntado Enríquez por la instrucción secreta, éste dijo que era el reconocer las fuerzas de los fuertes, artillería, guarniciones y embarcaciones de guerra, y que procurasen, en caso de tener aviso, volverse por el estrecho de Anian que está por descubrir, y que no se volviese por el mismo camino $^{32}$. Chile, por lo tanto, formaba parte de un plan global de Inglaterra que contemplaba su presencia en ambos océanos.

Aunque dice que el viaje de su comando no pretendía más que obtener las noticias referidas y establecer comercio con los naturales de estas partes no siendo sujetos a la corona de España, declaró

También ANH, Fondo Morla Vicuña (en adelante MV), Vol. 20, pza. 9.

30 Declaraciones tomadas en Valparaíso, 12 de marzo de 1671. BN, SM, MM, 161, Dcto. 3221.

31 He buscado documentación inglesa relativa al contexto de este viaje y los planes de esa Corona, años antes y después de él, en la British Library, en el archivo y biblioteca del National Maritime Museum, y en los fondos Admiralty y State Papers, del The National Archives, en Londres, pero no he podido, hasta ahora, encontrar algo muy significativo. La documentación inglesa relativa a la expedición y las expectativas puestas en él, así como la evaluación de sus resultados, hubiera sido información riquísima para comprender mejor las implicancias de esta coyuntura, agregando la valoración de aquella corona sobre el Pacífico Sur.

32 Declaraciones tomadas en Valparaíso, 12 de marzo de 1671. BN, SM, MM, 161, Dcto 3221. 
Enríquez que las máximas y secretos del rey y de su consejo de estado no las sabe, y por lo que tiene entendido le parece enviará a poblar y fortificar en las partes que le pareciere mas convenientes, como lo ha hecho por la parte del norte en cuatro plazas que tiene fortificadas, como son la isla de la Magdalena, Barbudas, Carolina y la bahía de Carlos que se estaba tratando de poblar. Por eso, debía regresar con el armada y gente de guerra y familias que se hubiese de conducir a los puertos de América que me pareciesen convenir, poblar y fortificar para el seguro de las navegaciones y comercios $^{33}$. Sabemos, por Barros, que él mismo fue quien propuso poblar, pero no dijo aquí que la idea fue suya.

Se explica el intento inglés en conocer el estado de la plaza de Valdivia por la importancia que había cobrado con la ocupación holandesa y la refundación española, siendo un axioma [dice Gabriel Guarda] que cualquier intento contra el virreinato exigía previamente la ocupación de Chile; dentro de esta cosmovisión Valdivia era estimado el antemural por excelencia ${ }^{34}$. Sabían los ingleses, asimismo, que los indígenas de Chile se habían rebelado y expulsado a los españoles (Chile español había sido reducido a la mitad en 1598) y se interpretaba, entonces, como una posibilidad de amistarse y con su venia instalarse en los territorios dominados por ellos -y no por los españoles-, lo que no supondría desmedro para estos últimos. Interesaba esta alianza para practicar el comercio (se pensaba que podrían pagar en oro). Este plan de tomar Valdivia se reactivó en 1741, cuando tuvo lugar la expedición del inglés George Anson ${ }^{35}$. Sobre el viaje efectivamente realizado, dice que se había reconocido bien el camino a través del estrecho de Magallanes; que había tomado posesión de todas las tierras, desde puerto Deseado al sur, en nombre del rey de Inglaterra al son de clarinetes y tiros de artillería y bastimentos de banderas y aclamaciones

33 Idem.

34 Guarda 2001, op. cit., p. 179.

35 Williams, G. (2002). El mejor botín de todos los océanos. La trágica captura de un galeón español en el siglo XVIII. Madrid, España: Turner Publicaciones, p. 72.

36 Declaraciones tomadas en Valparaíso, 12 de marzo de 1671. BN, SM, MM, 161, Dcto 3221.

37 Bradley 1986, op. cit., p. 467. Cita los Autos. AGI, Lima, 73.

38 Gil 1989, op. cit., p. 299.

39 Ibidem, p. 300. Habría que añadir, a lo dicho por Gil, que de viva el rey ${ }^{36}$.

No se puede dejar de mencionar que Enríquez, estando en Concepción dijo que el verdadero móvil -oculto al rey de Inglaterra- había sido venir a prestar apoyo al saliente gobernador, Francisco Meneses (quien estaba acusado y muy desacreditado en el reino) ${ }^{37}$. Juan Gil, que se ocupa de esta expedición en el contexto de la creencia en la Ciudad de los Césares -colonias ocultas de descendientes o de antiguos náufragos españoles, o de los sobrevivientes de las colonias del Estrecho fundadas en 1584; o de extranjeros-, afirma que Enríquez llegó a Chile a auxiliar a Meneses en su supuesto plan para hacerse de las también supuestas minas de oro que se asociaban a esta ciudad o territorio, que Meneses -dice Gil- creía estar ubicada en el área del estrecho de Magallanes, lo que explica el cuidado sondaje hecho por la Sweepstakes ${ }^{38}$. Páginas más adelante sostiene, refiriéndose al limeño traidor Diego de Peñalosa, que el viaje respondía a un plan perfectamente organizado en apariencia por el visionario limeño, quien después de incógnitas peripecias trataba de descubrir en servicio de Inglaterra el reino de los Césares: la quimera podía mover montañas ${ }^{39}$. Es muy interesante el espléndido ejercicio de interpretación que hacen, separadamente, Gil y Bradley, acerca de los intereses particulares detrás del viaje oficial, porque están asociadas al imaginario del territorio entre Magallanes y Valdivia.

b. Noticia dada desde Valdivia, 1670 y acciones del virrey del Perú, 1671

Antes de tocar Narborough costas americanas, el gobernador de la isla de Santo Domingo había avisado al de Panamá que iban a pasar al Mar del Sur algunos navios de guerra de Inglaterra ${ }^{40}$, muy probablemente enterado a través de las islas Madeiras, donde los barcos de Narborough hicieron escala. El gobernador de

Carlos Enríquez habló expresamente de los Césares: dijo que el rey de Inglaterra también le encargó que solicitase el descubrimiento de una población en el estrecho de Magallanes en el que dicen haberse retirado los españoles que el general Don Pedro Sarmiento trajo para poblar las dos ciudades. Declaraciones tomadas en Valparaíso, 12 de marzo de 1671. BN, SM, MM, 161, Dcto. 3221.

40 "Relación del socorro que el excelentísimo señor conde de Lemos, virrey del Perú, envió a tierra firme para desalojar de Panamá al pirata inglés con otros sucesos de aquel reino", sin fecha. BN, SM, MM, 161, Dcto. 3249. 
Panamá se lo comunicó al virrey del Perú, conde de Lemos, quien en consecuencia previno no solo a los puertos del Perú sino también a los de Chile y Valdivia, por ser los más próximos al estrecho de Magallanes ${ }^{41}$, y envió a la plaza un nuevo gobernador (Pedro Ruiz de Montoya) y sargento mayor (Juan Delso), el situado de 140.000 pesos, nuevas reclutas de gente, artillería, víveres, municiones y demás pertrechos. Con ello -dice el mismo documento- se consiguió la apertura del camino entre Concepción y Valdivia, en pleno territorio araucano, cerrado hasta entonces para el tránsito de españoles ${ }^{42}$. Envió a Chile el barco Santo Tomás de Villanueva, al mando de Martín Ochoa de Achuri, para vigía y para conducir el situado y socorro ya dicho, en dos viajes desde el puerto de Valparaíso, quien reconoció también el archipiélago de Juan Fernández ${ }^{43}$. Pero Ochoa de Achurri no vio nada, porque cuando ejecutó el viaje, en 1670, Narborough aun no llegaba a Valdivia: se había quedado casi un año entre Puerto Deseado y San Julián.

El 31 de diciembre de 1670 (el día que Narborough se volvió a Inglaterra desde Valdivia) el gobernador de Chile, Juan Henríquez, que lo era desde hacía cuatro meses, y que estaba en las cercanías de Concepción atendiendo los asuntos de la Frontera de Chile, envió una urgente comunicación a las autoridades del puerto de Valparaíso, porque había recibido la noticia de cómo sobre Valdivia se hallaban doce navios de guerra ingleses que la estaban batiendo ${ }^{44}$. Ese mismo día escribió alertando de los diez o doce navios al gobernador de Buenos

41 Idem.

42 Idem.

43 El capitán Bartolomé Iñiguez de Ciriano, escribano mayor de la Real Hacienda, minas y registros. Valparaíso, 6 de enero de 1671. British Library, Add. Ms. 21.539, Spanish American Papers, Melfort Papers.

44 "Relación del socorro que el excelentísimo señor conde de Lemos, virrey del Perú, envió a tierra firme para desalojar de Panamá al pirata inglés con otros sucesos de aquel reino". BN, SM, MM, 161, Dcto. 3249.

45 Idem.

46 Sin fecha ni identificación, excepto la que se da de este documento en el catálogo: "Relación de cartas, decretos y consultas sobre el peligro inglés en América Meridional", ANH, MV, Vol. 5, pieza 48, fjs. 172-176v.

47 El capitán Bartolomé Iñiguez de Ciriano, escribano mayor de la Real Hacienda, minas y registros. Valparaíso, 6
Aires $^{45}$. No sabemos porqué desde Valdivia se informó que eran doce, o dónde fue que se produjo el error. En ese momento el Santo Tomás de Villanueva aún estaba en Valparaíso a punto de zarpar hacia el Callao, así que llevó la noticia al virrey ${ }^{46}$, quien, enterado el 23 de enero de 1671, envió de inmediato la alerta de peligro al gobernador de Panamá, Juan Pérez de Guzmán, porque justamente debo recelar que se diviertan solos puertos de este Mar del Sur y quieran invadir Panamá y que lo hagan por ambos mares ${ }^{47}$. Despachó dos barcos para la vigilancia, uno hacia el norte y otra vez uno hacia el sur, y dispuso que por tierra se avisase a La Plata, la Paz, Potosí, Tucumán, Paraguay y Buenos Aires.

A los pocos días el virrey supo del ataque del pirata inglés Henry Morgan al castillo de Chagres y luego a la ciudad de Panamá, donde llegó el 27 de enero de $1671^{48}$. Envió, por lo tanto, socorros ${ }^{49}$. Cuando un mes más tarde los ingleses abandonaron la ciudad, el virrey comunicó al rey que esto se había producido por haberse enterado los ingleses de los preparativos de ataque dispuestos por é ${ }^{50}$. Poco después, el 10 de mayo, llegó al Perú el barco vigía enviado a Chile con la noticia de estar el mar limpio de embarcaciones enemigas, y que si alguna hubiese intentado pasar el estrecho de Mayre, que se debió de perder porque no llegó a aquellos parajes, refiriéndose al segundo barco de Narborough ${ }^{51}$. Llevaba los cuatro ingleses capturados, incluyendo a Carlos Enríquez, del que se dice era portugués. A diferencia del gobernador de Valdivia, y del de Chile, en la capital del virreinato se creyó en las declaraciones de los ingleses, de quienes

de enero de 1671. British Library, Add. Ms. 21.539, Spanish American Papers, Melfort Papers.

48 El virrey del Perú, conde de Lemos, al presidente de Panamá, Juan Pérez de Guzmán. Lima, 24 de enero de 1671. British Library, Add. Ms. 21.539, Spanish American Papers, Melfort Papers. Considérense también la carta del virrey de 14 de febrero de 1671. AGI, Lima, 72.

49 El licenciado Don Pedro García de Ovalle al Sr. Diego Sarmiento de Valladares. Lima, 10 de mayo de 1671. BN, SM, MM, 161, Dcto. 3227.

50 "Relación del socorro que el excelentísimo señor conde de Lemos, virrey del Perú, envió a tierra firme para desalojar de Panamá al pirata inglés con otros sucesos de aquel reino". BN, SM, MM, 161, Dcto. 3249.

51 Idem. 
se ha sabido que sus designios no fueron de venir a hacer daño en estas costas ${ }^{52}$.

\section{NOTICIAS LLEGADAS DESDE LONDRES A MADRID, 1671-1672}

\section{a. El conde de Molina}

Como se ha dicho, en junio de 1671 Narborough llegó a Londres. En cartas sucesivas del mes siguiente el embajador español -Antonio de Tobar y Paz, conde de Molina- comunicó a la corte de Madrid la llegada de un barco inglés que había cruzado el estrecho de Magallanes ${ }^{53}$; que alguien llamado don Carlos Henríquez se había quedado en Chile, siendo muy de prevenir y recelar si sería voluntaria la retención de Carlos, y querer persuadir haber sido prisionero; y que sospechaba la real importancia de Carlos en la empresa, respecto es cierto que estuvo muchos años en dicho reino de Chile y haber entregado antes que partiese de aqui al duque de York una muy distinta relación del presente estado en que se hallaba dicho reino y de que sería el más considerable comercio de los que los ingleses tuviesen ${ }^{54}$. Sabía que habia hecho repetidas proposiciones al rey de Inglaterra sobre que intentase diferentes empresas en las Indias en perjuicio de esta corona ${ }^{55}$.

Informaba también que tenía una copia de la relación del viaje hecho por Narborough, y de su mapa, que más tarde envió a la corte ${ }^{56}$ (Fig. 1). Setenta años más tarde, la ya mencionada flota de George Anson hizo uso de parte de la información

52 El licenciado Don Pedro García de Ovalle al Sr. Diego Sarmiento de Valladares, 10 de mayo de 1671. BN, SM, MM, 161, Dcto. 3227.

53 Esa carta no la he hallado, pero la refiere en una posterior, de Londres, 24 de julio de 1671. ANH, Fondo Vidal Gormaz (en adelante VG), Vol. 11, pza. 32.

54 El conde de Molina a la reina. 10 de julio de 1671. ANH, CG, 715, fjs. 157 y $157 \mathrm{v}$.

55 Cédula de la reina al pdte. de Chile, Madrid, 30 de diciembre de 1671, AHN, CG, 715, fjs, 155 y 155v.

56 Todo indica que este mapa es el de AGI, Mapas y Planos, Buenos Aires, 226. Está catalogado como Anónimo, 1671. Tabla del procedimiento del viaje de una fragata y un patache ingleses al estrecho de Magallanes. Lo afirma también Guarda 2001, op. cit., p. 163.

57 Bulkeley, John y John Cummins, Voyage to the SouthSeas in the years 1740-1. Containing a faithful narrative of the loss of his majesty's ship the Wager on a desolate del diario de Narborough: estadía en Puerto Deseado; isla Guamblín como punto de encuentro luego del cruce interoceánico; y ataque a Valdivia como primer objetivo. Sabemos, además, que el capitán de la fragata Wager, parte de esa flota, que naufragó en una isla del archipiélago de Guayaneco, tenía un ejemplar del libro de Narborough, y que era codiciado por los desertores para planear su regreso a Inglaterra por el estrecho de Magallanes (en el viaje de ida habían seguido la ruta del cabo de Hornos) en una de las embarcaciones auxiliares ${ }^{57}$. Lo acredita también Helen Wallis, cuando dice que el diario de Narborough permaneció por muchos años como la guía estándar del Estrecho ${ }^{58}$.

El conde de Molina supo que se estaba preparando un segundo viaje con el mismo designio que el anterior, es decir tomar el puerto de Valdivia $u$ otro de no menor importancia, incitado también por el ya nombrado Diego de Peñalosa, limeño estante en Inglaterra que -dice- persuadió del ataque a Panamá, y que se ha ofrecido a ir a conseguirlo (el viaje a Chile $)^{59}$. La recomendación del conde de Molina da cuenta de lo poco o nada que se conocía el territorio austral: dice que están ocupados todos los puertos de la costa del Mar del Sur por los pueblos que viven bajo la obediencia de V.M. ${ }^{60}$; y que como estos pueblos están sin recelo de alguna hostilidad de enemigos y sin fuerza ni disposición para hacer oposición a los que quisieren pasar a aquellos mares por este nuevo rumbo, muy fácilmente podrán los ingleses $u$ otra cualquier nación tomar puerto y fortificarse en él con el pretexto de decir ser de indios, y una vez fortificados no hay duda que fomentarán el

island in the latitude 47 South, longitude 81:40 West, London, printed for Jacob Robinson, Publisher, 1743. Citamos aquí la versión: Byron, J., Bulkeley, J., Cummins, J., Morris, I., \& Campbell, A. (2012). Cuatro relatos para un naufragio. Los protagonistas de la Wager en el golfo de Penas en 1741. Santiago, Chile: Septiembre Ediciones, p. 128.

58 Wallis, H. (1965). English Enterprise in the region of the Strait of Magellan. En J. Parker (Ed.), Merchants \& Scholars. Essays in the history of exploration and trade (pp. 195- 220). Minnesota, Estados Unidos de América: University of Minnesota.

59 El conde de Molina. 10 de julio de 1671. ANH, CG, Vol. 715, fjs. 157 y 157v. También lo trata Guarda, Gabriel, Nueva Historia, op. cit., p. 183.

60 El conde de Molina asume erróneamente que los indígenas están sujetos a la corona por un juramento de fidelidad. 


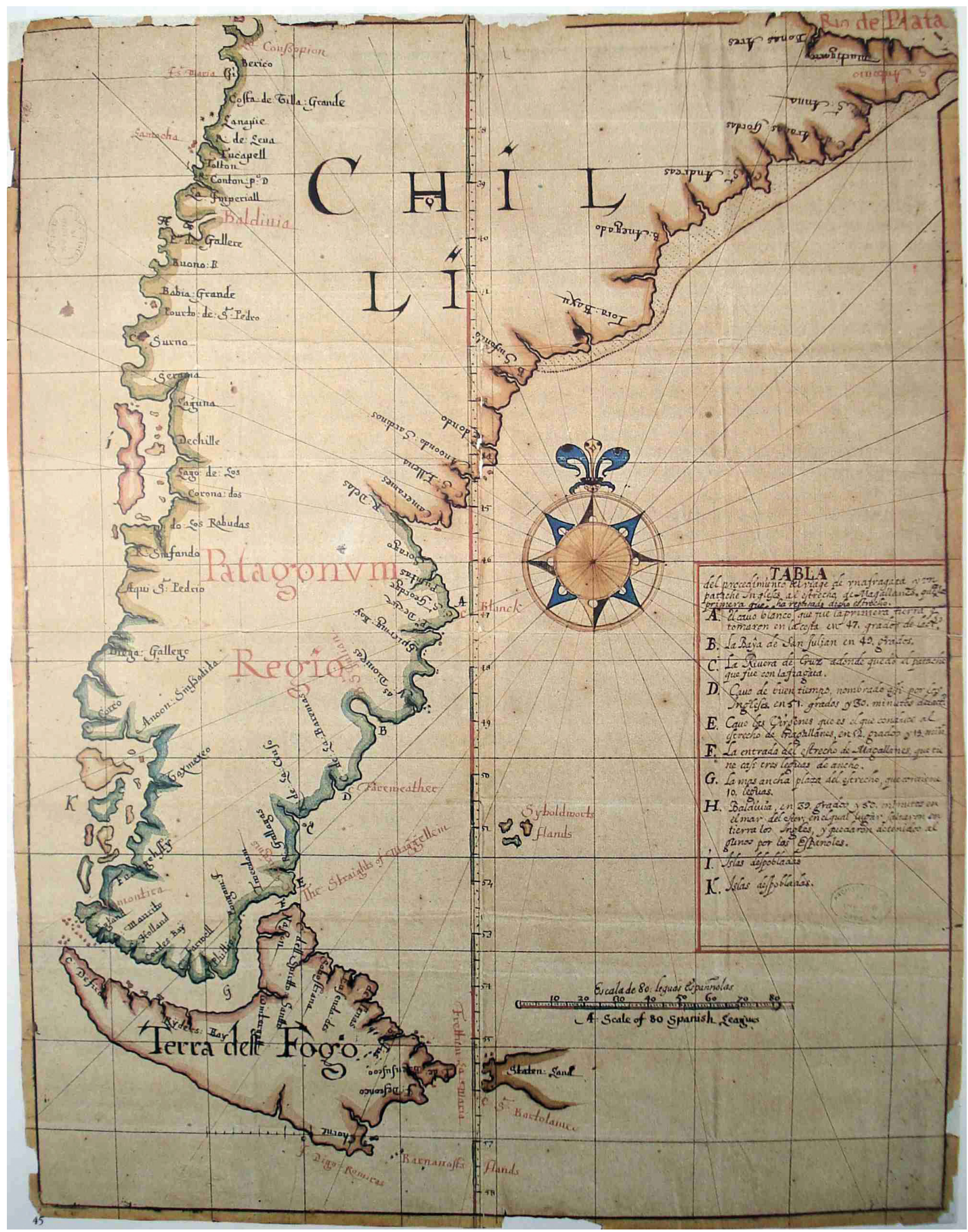

Fig.1. AGI, Mapas y Planos, Buenos Aires, 226. Anónimo, 1671. Tabla del procedimiento del viaje de una fragata y un patache ingleses al estrecho de Magallanes. 
trato y comercio y que divertirán mucha parte de los tesoros de vuestra majestad ${ }^{61}$. Por no conocerlo es que sugirió poner una llave en esta puerta (estrecho de Magallanes), mediante un castillo, sin saber la real distancia entre el Estrecho y Chiloé, y sin considerar tampoco que el de Magallanes era solo uno de varios pasos interoceánicos. Esto mismo había sido propuesto por Sarmiento de Gamboa, luego del paso de Drake ${ }^{62}$.

Al parecer el castillo era una opción, y junto a ella propuso un más eficaz, breve o menos costoso medio, que es el ya experimentado con ostendeses y vizcaínos... en tiempo de Cromwell, y es el dar cartas de marca, o licencias para apresar barcos enemigos. Con ello se permitiría apresar a cualquier navio extranjero que se topase pirateando en aquellos mares, y trayéndolos a nuestros puertos sólo se condenarían de buena presa los que fuesen comprendidos en las patentes de V.M., de que se seguirá el castigo de los que le mereciesen, y que viendo éstos interrumpidos y arriesgando su comercio, se hallarían obligados de clamar... ${ }^{63}$. El consejo de Estado opinó desestimando la propuesta por lo difícil y lejano. Se dudaba que los castillos bastasen para la defensa. No sabemos la opinión del Consejo de Indias, ni tampoco las órdenes enviadas a las autoridades de América luego de la noticia de conde de Molina. Finalmente, en pleno período de sospechas que aquí retratamos (1671-1683), tampoco la Corona dispuso otra acción que la simple vigilancia hacia el Estrecho desde Chiloé, y tanto esas acciones (en realidad, no acciones) como las opiniones, dan cuenta del completo desconocimiento de las tierras magallánicas, grado de sujeción de sus habitantes originarios, posibilidades de instalar allí una

61 El conde de Molina a la reina, Londres, 14 de julio de 1671. BN, SM, MM, 161, Dcto. 3229. También en ANH, VG, Vol. 11, pza. 32.

62 Véase Zuleta, J. (2013). La fortificación del estrecho de Magallanes: un proyecto al servicio de la imagen de la monarquía. Revista Complutense de Historia de América, 39, 153-176, pp. 166-167.

63 El conde de Molina a la reina. Londres, 14 de julio de 1671. BN, SM, MM, 161, Dcto. 3229.

64 Era un mapa de todo el mundo y que llegando a la descripción del reino de Chile, dice lo que contiene el papel que remite el conde. Se trataba del Atlas Maritimus or A book of charts describeing the sea coasts, capes, headlands, sands, shoals rocks and dangers the bayes roads, harbors, rivers and ports, in the most of the knowne parts of the world..., datado actualmente como Londres, 1670?. En la colonia (española o inglesa), y distancia y calidad de la costa austral entre Chiloé y el confín del continente.

\section{b. Noticias impresas sobre Chile, 1671}

En carta del conde de Molina de 4 de septiembre de 1671 informó a la reina, Mariana de Austria, de haberse publicado recientemente en Londres un libro con mapas del mundo, del cosmógrafo de Carlos II, John Seller. En él se dio cuenta del viaje de Narborough, el que dio grandes esperanzas de poder tener un tráfico en aquellas partes que quizá será de gran ventaja a todo este reino respecto de la gran cantidad de oro y plata que hay en aquella tierra ${ }^{64}$. Se informó sobre el itinerario seguido (río San Julián, puerto Deseado, estrecho de Magallanes, isla Guamblín y Valdivia); la fácil navegación del Estrecho; que el poder y jurisdicción de los españoles los cuales tienen el mando de dicho paraje [Valdivia], es hasta donde alcanza su artillería; y que hay amplias posibilidades de comerciar con los indios, quienes se avendrían al comercio por causa de un disgusto que tienen contra los españoles por su crueldad e infidelidad. El conde de Molina envió, traducida al español, la parte relativa a Chile. Pasaron menos de tres meses entre la llegada de Narborough y el haber salido de imprenta el Atlas ${ }^{65}$.

$\mathrm{Ni}$ la noticia de que saldría una flota para continuar lo comenzado por EnríquezNarborough, como lo había anunciado el conde de Molina en julio de 1671, ni tampoco lo publicado por Seller, fue causa de que se enviara una flota española a vigilar el Estrecho66. La Corona nada dijo, además, acerca de los

primera edición se publicaron 26 mapas, pero en lo sucesivo todas las copias y ediciones varian en contenido. https:// archive.org/details/atlasmaritimusor00sell. También: https:// library.villanova.edu/Find/Record/1192105.

65 Traducción de una parte del libro de John Seller, adjunto a una carta del conde de Molina. Consulta del consejo de Estado a la reina, 21 de octubre de 1671. BN, SM, MM, 161, Dcto. 3241. La traducción es el documento 3242 , y es puntualmente lo publicado. Por lo tanto, el Londres, 1670 ? no podría ser (Narborough llegó de regreso en junio de 1671), sino, Londres, 1671.

66 Sobre las preocupaciones de la corte en la época, véase: Sánchez, J. (1999). Las relaciones internacionales de la monarquía hispánica durante la regencia de doña Mariana de Austria. Studia Historica. Historia Moderna, 20, 137172 . 
patagones. ¿Porqué se les mantuvo en sus tierras y no hubo intención de evangelizarlos o de trasladarlos a Chiloé, durante todo el período colonial, a pesar de saberse que siempre intercambiaban con los extranjeros? La efectiva defensa, en realidad, fue el saber España $e$ Inglaterra de la falta de atractivos económicos de las costas magallánicas y pacífico-australes (exceptuando iniciativas como la que aquí se trata). En cuanto a las autoridades indianas, el virrey del Perú, a propósito de la efectiva estadía de un barco inglés a la entrada de Valdivia, y la atención que presta al mismo tiempo a Panamá, dispuso la vigilancia por medio de un barco entre la amenazada Valdivia, el archipiélago de Juan Fernández y Panamá. Le interesa resguardar las costas virreinales cercanas a Perú y nada dice del Estrecho.

Una nueva alarma llegó a Madrid, cuando el 4 de diciembre de 1671 el irlandés Ricardo White presentó a la corte un memorial en el que hacía ver el peligro en el que estaba Valdivia, e informaba que Diego de Peñalosa estaba en Londres, haciendo creer a las máximas autoridades lo fácil que sería ganar algunas plazas a los españoles en el Perú ${ }^{67}$. No se sabía, como sabemos hoy por Gil, cuánto este Peñalosa estaba relacionado con Enríquez.

Hubo más avisos. Con fecha 28 de marzo de 1672 el nuevo embajador en Londres, Pedro de Velasco y Tovar, marqués del Fresno, avisó a la reina que se aprestaban seis navíos para pasar a Jamaica, unirse con los que hubiere en Indias y apoderarse de la isla de Santo Domingo, o del castillo de Chagres, y pasar a hostilizar el reino del Perú, en el Mar del Sur, y con el conocimiento que tienen de la entrada a él por la parte de Valdivia, cuyo paraje reconocieron el año de 670, tengo por sin duda no dejarán de intentar tomar tierra para cerrar estas dos puertas al Perú que tanto daño y tan difícil de remediar sería si lo llegasen a lograr, cuya invasión no dudo procurarán hacerla... ${ }^{68}$.

67 Gil 1989, op. cit., p. 300. Gil refiere las fuentes de AGI, Indiferente General, 1877. También AGI, Chile, 23.

68 El marqués del Fresno a la reina. Londres, 28 de marzo de 1672. The National Archives, State Papers 94: State Papers Foreign, Spain, 1577-1780.

69 El gobernador de Chile a la reina. Santiago, 27 de diciembre

\section{NUEVA ALARMA DESDE LONDRES Y REACCIONES CONSECUENTES, 1673-1675}

\section{a. ¿Henry Morgan en Chile?, 1673}

Casi un año más tarde, y otra vez desde Londres, en diciembre de 1672 o enero de 1673, el marqués del Fresno informó a la reina -dos años después de haber sabido del regreso de Narborough- que se estaban aprestando en la ría de Londres tres bajeles a cargo de Enrique Morgan, piratas, para ir a infestar estos mares 69. Se dice que pasará a infestar las costas, pero no se dice nada del Estrecho. La reina puso en alerta al virrey, quien además de estos navíos, sin que sepamos con precisión cuándo, también recibió el aviso de los cinco que se habían visto en las Canarias $^{70}$. Alertó también al gobernador de Chile, Juan Henríquez, en carta de 13 de enero de 1673, que fue recibida en diciembre de ese año, y respondida el 27 de diciembre: dijo el gobernador que ya tenía prevenida toda la costa y puertos con mil caballos escogidos, 800 infantes y mil indios de lanza, y se agregarán a esta caballería española, para defender si llegase la ocasión. En caso de necesidad, las milicias de los partidos de Santiago acudirán a Valparaíso ${ }^{71}$.

Hasta ahora, podemos ver que el recelo que tenía la corte de Madrid estaba provocado por las noticias dadas por sus embajadores e informantes en Londres, y era que -se decía en 1671- los ingleses instalasen una colonia en el estrecho de Magallanes, o, se decía en 1673, que atacasen puertos y barcos. No ordena ninguna acción específica, como ocupar el Estrecho o destinar una flota desde España, sino que solo espera que se protejan los puertos de Chile.

Nada sabemos del año 1674, salvo en diciembre, en que en una carta al virrey, el 6 de ese mes y año, el gobernador Juan Henríquez volvió sobre el asunto de los navíos en la ría de Londres para informar que ve preciso reforzar los fuertes de Concepción y Arauco, que están en la costa, sin

de 1673. BN, SM, MM, 163, Dcto. 3311.

70 El virrey del Perú a la reina. Lima, 28 de abril de 1675. AGI, Chile, 23, R.3, N.83.

71 El gobernador de Chile a la reina. Santiago, 27 de diciembre de 1673. BN, SM, MM, 163, Dcto. 3311. 


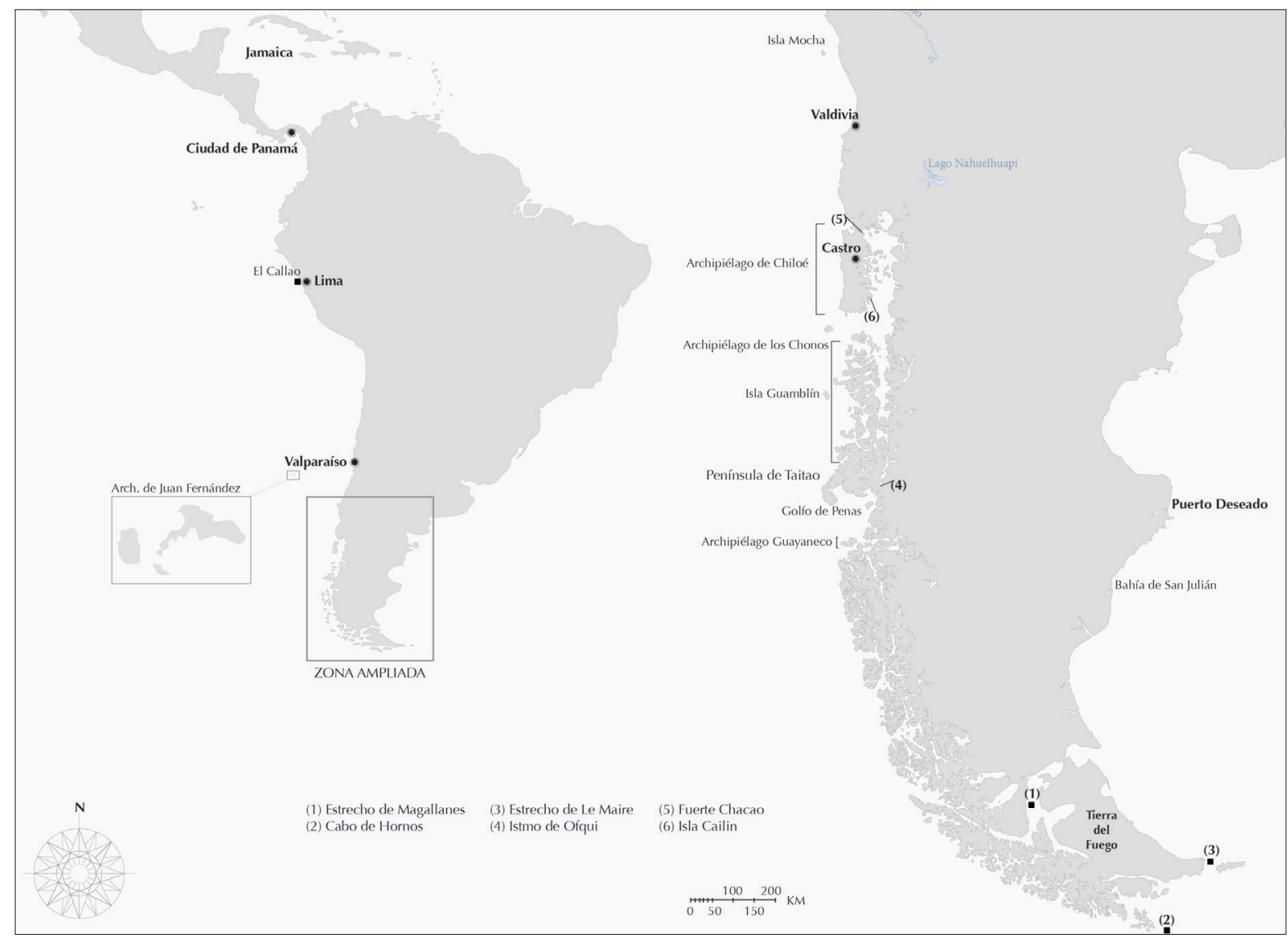

Fig. 2. Mapa del territorio entre el río Bío Bío y el cabo de Hornos. Hecho por Camila Fuenzalida Polanco.

desamparar los fuertes de la tierra adentro; y retirar a los indígenas hacia el interior, por la poca seguridad que tengo de estos indios, pues siempre que puedan darse la mano con los ingleses lo ejecutarán. Henríquez opinó, en esta ocasión, que en las costas de Chile era muy poca o ninguna la utilidad que podían tener los ingleses, debido a la cortedad de lo posible de saquear en los puertos de Valparaíso y Coquimbo: lo mas que pueden saquear es sebo, y todos sus edificios son cuatro bodegas, y Coquimbo era país es muy estéril de viveres... y caso que llegasen a él le abandonarian con brevedad ${ }^{72}$. Se ve cómo el gobernador utiliza la coyuntura externa para tratar asuntos internos. Celebró una junta general con los caciques araucanos, aunque expresó que vivía con desconfianza de su palabra. Envió a Chiloé a vigilar las costas hacia el Estrecho, como veremos a

72 El gobernador de Chile, Juan Henríquez, al virrey del Perú, Santiago, 6 de diciembre de 1674. AGI, Chile, 23, R.3, N.83.

73 Vázquez de Acuña, I. (1993). La jurisdicción de Chiloé (siglos continuación. Ni en las órdenes de España ni en las de Lima se menciona Chiloé.

\section{b. Vigilancia desde Chiloé, 1674-1676}

La documentación no señala, al menos lo que he encontrado, si Chiloé había sido informado de algo hasta entonces, pero es de suponer que si: al menos lo habrá sido de los doce navíos en Valdivia. La documentación chilota tampoco dice que hayan vigilado, hasta esa fecha, las costas hacia el estrecho de Magallanes, territorios que eran parte de la jurisdicción del gobernador de Chiloé, la provincia más austral de Chile ${ }^{73}$. Hasta los sucesos que aquí trato, la Corona nunca ordenó que Chiloé o el virreinato del Perú poblasen o

XVI al XX). Su extensión, exploración y dominio. Boletín de la Academia Chilena de la Historia, 103, 111-119. 
vigilasen el Estrecho, excepto en la coyuntura de Francis Drake y colonias de Pedro Sarmiento de Gamboa (1578-1584). Tampoco hubo en Chiloé intención de disponer una vigilancia permanente hacia él. La distancia es considerable, pero además, desde Chiloé se conocía mejor que en ningún otro lugar que cualquier establecimiento allí sería un punto en la inmensidad de esos parajes, poblados por etnias a las que por su lejanía y pobreza no interesó ni conocer ni trasladar para su españolización. Chiloé, eso si, se proyectó hacia el sur -archipiélago de los Chonos e incluso más al sur de la península de Taitao- con fines misionales (búsqueda $y$ traslado de chonos para su evangelización ${ }^{74}$ ) y económicos (razias esclavistas de chonos; explotación de naufragios ${ }^{75}$ ). Es de suponer que estaban informados de las costas, porque tenían un sistema de vigilancia en base a indígenas, como es evidente en el siglo XVIII, de la que por interna, no debiese darse cuenta al gobernador de Chile o al virrey ${ }^{76}$. La comunicación con las islas de los Chonos, y los chonos, era antigua y natural, y los chonos llegaban a Chiloé a comerciar ${ }^{77}$. Pero también, en Chiloé no se sospechaba de bases inglesas en su frontera sur, porque los ataques holandeses a Castro, en 1600 y en 1643 habían demostrado que el objetivo eran los asentamientos españoles, y no el improductivo, lejano y vacío austro. Luego, este argumento se reprodujo (el que Chiloé es importante, y no el sur de ella) desde al menos el año 1684, cuando desde la propia isla se pidió su despoblación, por no exponerla a los ingleses, y traslado de los habitantes a Chile, y cuando

74 Urbina, M. X. (2016). Traslados de indígenas de la Patagonia occidental insular a Chiloé en los siglos XVI, XVII y XVIII. En J. Valenzuela (Ed.), América en diásporas: esclavitudes y migraciones forzadas (siglos XVI-XIX). Santiago, Chile, Pontificia Universidad Católica de Chile/RiL editores (en prensa).

75 Urbina, M. X. (2015). El naufragio de la Wager en el Pacífico austral y el conflicto del hierro en Chiloé. En R. Sagredo y Moreno, R. (Eds.). El Mar de Sur en la Historia. Ciencia, expansión, representación y poder en el Pacífico (pp. 239-278). Santiago, Chile: Centro de Investigaciones Diego Barros Arana, Dirección de Bibliotecas, Archivos y Museos, y Universidad Adolfo Ibáñez.

76 Urbina, M. X. (2013). Expediciones a las costas de la Patagonia occidental en el período colonial. Magallania, 41(2), 51-84. en 1749 el gobernador de Chiloé pidió mas atención y defensa para la isla, aprovechando la coyuntura de lo alarmada que estaba la corte cuando se enteró, por noticias recibidas desde Londres, que una flota inglesa al mando de George Anson había recibido la colaboración de los indígenas de los archipiélagos australes, refiriéndose al naufragio de la Wager y la estancia por dos meses del Anna en una bahía de la península de Taitao ${ }^{78}$.

Muy probablemente como consecuencia de la carta avisando sobre Morgan, que como ya se ha dicho, fue escrita en enero y recibida en diciembre de 1673, el gobernador de Chile envió en enero o febrero de 1674 el barco Nuestra Señora de Begoña a Chiloé, para desde allí vigilar las costas hasta el Estrecho. Una vez llegado a la provincia insular su capitán, Juan de Ávalos, debido a los peligros del mar en esas costas no se atrevió a ponerlo en ejecución ${ }^{79}$. Entonces, el gobernador de Chiloé, Francisco Gallardo, puso al mando a un sargento mayor de la plaza, Jerónimo Diez de Mendoza, con la orden a que reconociese todo lo posible la costa de dicha provincia hasta el dicho estrecho de Magallanes ${ }^{80}$. Diez de Mendoza llegó hasta una latitud indeterminada (no hay diario ni explicación de esta expedición, sino apenas una corta referencia a ella en una carta ${ }^{81}$ ) y regresó a Chiloé en febrero o marzo de 1674 sin haber visto nada extraño, pero llevando consigo algunas lenguas de los parajes del sur que le habían servido de informantes. Como se ha señalado más arriba, en Chiloé no se sospechaba de la presencia de extranjeros en su frontera sur.

Enjunio de 1674 uno de ellos, identificado como

77 Urbina, M. X. (2016). Interacciones entre españoles de Chiloé y chonos en los siglos XVII y XVIII: Pedro y Francisco Delco, Ignacio y Cristóbal Talcapillán, y Martín Olleta. Chungara, 48(1), 103-114.

78 Urbina, M. X. (2014). El frustrado fuerte de Tenquehuén en el archipiélago de los Chonos, 1750: dimensión chilota de un conflicto hispano-británico. Historia, 47 (1), 133-155.

79 Gallardo, B. (1886). Relación del sargento mayor Don Bartolomé Gallardo hecha en Lima de orden de V. E. sobre el viaje que hizo en reconocimiento a las poblaciones de los ingleses con todo lo sucedido en él y paraje donde llegó (1674-1675). Anuario Hidrográfico de la Marina de Chile, 11, 525-537, p. 526.

80 Idem.

81 El gobernador de Chiloé. Chacao, 29 de octubre de 1674. AGI, Chile, 7. 
de la etnia chona, llamado Talcapillán, estante como los demás en el fuerte de Chacao, reveló a una mujer, y luego a quien lo quisiese escuchar, que desde hacía pocos años atrás existían dos poblaciones fortificadas, una en una isla y otra en la tierra firme inmediata, más al sur del istmo de Ofqui, llamadas Allauta y Callanac, hechas y habitadas por moroguincas ${ }^{82}$. Describía con detalles cada una de ellas, su tamaño, ocupaciones de sus habitantes, producciones de alimentos, vestimentas, su constante comunicación marítima con Inglaterra, alianzas con unos indígenas locales y las hostilidades que tenían con otros, y hasta la apariencia de ambos gobernadores. Y, agrega Gallardo, no contento con esto, pinta en el suelo y paredes su tierra e islambres de ella, con distinción las que goza el enemigo y sus fortificaciones, las derrotas que han llevado los nuestros en diversas ocasiones y lo errado que anduvieron para llegar a las partes que hoy dice tiene el enemigo por suyas ${ }^{83}$. Fue interrogado por el gobernador de Chiloé, quien, solo después del invierno pudo avisar de todo al presidente de Chile y al virrey, cuando también envió una nueva expedición al mando de su hijo Bartolomé, llevando al chono Talcapillán -bautizado como Cristóbal- como guía, entre octubre de 1674 y febrero de 1675.

82 Huincas moros, es decir, extranjeros que no eran españoles (católicos)

83 El gobernador de Chiloé. Chacao, 29 de octubre de 1674. AGI, Chile, 7. Son 10 fojas sin numerar. También en AGI, Chile, 23, R. 3, N. 83. De esta carta y algunas de las siguientes hay copia en ANH, MV, Vol. 4, piezas 187-191 y 193-195.

84 Las dalcas eran embarcaciones de los indígenas de Chiloé, hechas de tres tablas cosidas a las que se le daba la forma conveniente. Por marineras y eficientes, los españoles las adoptaron y adaptaron, llamándolas piraguas, como se llamaba usualmente en América a las embarcaciones indígenas. Véase Lira, N., Legoupil, D. (2014). Navegantes del sur y las regiones australes. En C. Aldunate (Ed.), Mar de Chile (pp. 102-143). Santiago, Chile: Ediciones del Museo Chileno de Arte Precolombino.

85 Gallardo 1886, op. cit., pp. 525-537.

86 "Relación diaria del viaje marítimo y descubrimientos de las costas del sur que hizo por orden el excelentísimo señor conde de Castellar, marqués de Malagón, virrey, gobernador y capitán de estos reinos del Perú, Tierra Firme y Chile, el capitán de mar y guerra Pascual de Iriarte, en el navío Nuestra Señora del Rosario, que continuó en el de la Santísima Trinidad, desde la provincia de Chiloé hasta el estrecho de Magallanes y Tierra del Fuego, por el recelo de las poblaciones que se suponían hechas por el inglés en aquellas costas, siendo piloto mayor el capitán Guillermo Bautista de Echavarría. Año de 1675”. Archivo del Museo
Navegaron en dalcas ${ }^{84}$ por el archipiélago de los Chonos y cruzaron con ellas desarmadas el istmo de Ofqui. Al otro lado, en el golfo de Penas, volvieron a armar sus embarcaciones y continuaron hacia el sur ${ }^{85}$.

Gallardo y su gente regresaron a Chiloé en febrero de 1675, sin novedad alguna, y luego navegaron a Lima -Talcapillán incluido- a informar al virrey, conde de Castellar. Aunque nada hallaron, Talcapillán aseguraba haber estado muy cerca del objetivo. El virrey habilitó una nueva e inmediata expedición, a cargo de Antonio de Vea, junto a Pascual de Iriarte, quienes zarparon desde Lima, y luego, desde Chiloé en noviembre 1675. Como Gallardo, Vea cruzó el istmo de Ofqui, mientras que Pascual de Iriarte navegó por fuera ${ }^{86}$. Ambos recorrieron el litoral austral hasta altas latitudes, sin hallar nada, pero con la decepción -o alivio- de la confesión de Talcapillán, quien dijo que todo esto lo había dicho porque le parecía que gustaban los españoles de esto, y que nunca creyó que llegásemos tan adelante ${ }^{87}$. Regresaron a Chiloé en marzo de 1676, y Vea hizo los únicos mapas coloniales de las costas australes, conocidos al menos, hasta los hechos por José de Moraleda más de cien años después ${ }^{88}$. Talcapillán es un personaje que merece atención aparte $e^{89}$.

Naval de Madrid (en adelante AMNM), Ms. 191, fjs. 3969.

87 Relación diaria del viaje que se ha hecho a las costas del estrecho de Magallanes, en el recelo de enemigos de Europa, por Don Antonio de Vea, Año de 1675. AMNM, Ms. 199, fjs. 576-619, f. 606. Colección Fernández Navarrete, Tomo XX. Este diario fue publicado en Vea, A. (1886). Anuario Hidrográfico de la Marina de Chile, 11, 539-596.

88 Antonio de Vea, 1676. Tres mapas de 55 x $41 \mathrm{cms}$. Gabriel Guarda los dio a conocer en 1981, en su Atlas cartográfico del Reino de Chile. Siglos XVII-XIX. Santiago, Chile: Instituto Geográfico Militar, de la copia de ellos que hizo de la Biblioteca Nacional de Lima, en 1971, según dice en la p. 78 del libro Monumenta Cartographica Chiloensia, que publicó el 2008 junto con Rodrigo Moreno. Dice, en esa nota, que hoy están extraviados.

89 Urbina, M. X. (2015). El chono Cristóbal Talcapillán y su información sobre colonias inglesas en la Patagonia Insular, 1674. Boletín de la Academia de Historia Naval y Marítima de Chile, 19, 27-44. Agrego aquí algo que no informé en el artículo que acabo de citar: Por la magnilidad de Talcapillán, como escarmiento y ejemplo se le dieron 200 azotes por las calles de Lima, y durante dos días se le expuso a la vergüenza en la plaza principal, amarrado a una argolla alta. Luego fue llevado al Callao, condenado a sacar piedra toda su vida para el reparo de aquellas murallas. BN, SM, MM, 235, Dcto. 6288. 


\section{c. Los intereses de Chiloé, 1673-1676}

Hasta aquí, entonces, se ejecutaron tres reconocimientos marítimos, litorales, salidos desde Chiloé, entre 1674 y 1676. Ninguno de ellos llegó al Estrecho. Solo el primer viaje respondió a la orden de vigilancia, pero los dos segundos no fueron ordenados por la corte, sino que fueron consecuencia de una información local (Talcapillán), y el reconocimiento, por lo tanto, no se hizo en el Estrecho sino en las costas anteriores a él, donde se suponía estaban ambas colonias: entre el golfo de Penas y la boca del Estrecho.

Coincidieron estos tres reconocimientos de Diez de Mendoza, Gallardo y Vea/Iriarte, con las cartas enviadas al gobernador de Chiloé por el jesuita Nicolás Mascardi desde la recién fundada misión del lago Nahuelhuapi (1670-1674), sobre los extensos territorios desconocidos y poblados por etnias que permanecían en la gentilidad, desde dicho lago hacia el sur hasta el Estrecho, hacia donde se dirigió en cuatro viajes. Creía Mascardi en los Césares. Esta coyuntura de los tres viajes, más los viajes terrestres de Mascardi, hicieron al gobernador de Chiloé recordar al de Chile y al virrey la importancia estratégica de la provincia insular, escindida del reino, pero puerta de entrada de la vasta región magallánica.

Los tres reconocimientos marítimos dichos son consecuencia del aviso llegado desde Londres en 1673 (que Morgan se dirigía al Mar del Sur), y éste, del de Narborough (que recomendaba poner una colonia o base inglesa en el estrecho de Magallanes). De esta forma, es una sospecha o recelo generado en Londres y recibido en Madrid el que obliga a Chiloé a reconocer una costa de la que hasta entonces no tenía sospecha de haber peligros. Pero esto activa a que los actores locales -en este caso, Talcapillán, como habitantes de las tierras no ocupadas por los españoles, y como tal, un instrumento para su conocimiento-, aumenten las sospechas recordando las antiguas creencias sobre poblaciones lejanas $e$ incomunicadas habitando la tierra firme entre Chiloé

90 Urbina, M. X. (2011). La proyección de Chiloé hacia la Patagonia Insular en el siglo XVIII. Anuario de Estudios Americanos, 68(2), 599-622.

91 Declaración de Alonso de Figueroa y Córdoba, Santiago, 2 de junio de 1681. BN, SM, MM, 166, Dcto. 3398. No nos detendremos aquí en ello, pero los jesuitas prestaron oídos, difundieron y buscaron la Ciudad de los Césares, especial- y el Estrecho, y que eran considerados Césares, que tanto interesaron a los españoles y jesuitas de Chiloé desde 1609, y especialmente a Mascardi ${ }^{90}$.

El alarmante relato de Talcapillán (conocido en Chiloé en junio de 1674) coincidió con la llegada a la isla de la noticia de la muerte de Mascardi (antes de octubre de ese año). De hecho, el gobernador insular Francisco Gallardo dio cuenta al rey de ambas novedades en la misma carta. Cuando los soldados de Chiloé que fueron enviados allende los Andes a recuperar el cuerpo del jesuita, preguntaron a los indígenas que le habían acompañado en su última travesía por lo ocurrido en ésta, ellos dijeron que los ingleses estaban poblados de esta parte del estrecho de Magallanes, y que Mascardi había visto un antiguo campamento de moroguincas. El gobernador del reino, entonces, despachó seis soldados a buscarlos, pero se halló no estar poblado el enemigo inglés. Volvieron, eso si, con el cuerpo de Mascardi ${ }^{91}$. La existencia de los Césares continentales de Mascardi coincidía con las noticias llegadas desde Inglaterra de posibles colonias en el extremo sur, y con las costeras de Talcapillán. La atención al confín austral era en esos años, por lo tanto, provocada tanto por indígenas como por ingleses, y a la vez pampeana y litoral.

Con estas noticias dadas personalmente por Talcapillán en Lima en marzo de 1675, se reactivó del caso de los prisioneros ingleses del barco de Narborough, que ya llevaban cuatro años en la capital virreinal, y se les tomaron nuevas declaraciones, preguntándoles cómo es que no habían visto en su paso, ni sabían, de las dos poblaciones de Talcapillán ${ }^{92}$.

Cuando se estaba ejecutando la expedición de Gallardo, el virrey Castellar nombró un nuevo gobernador de Valdivia, Francisco Delso (enero de 1675-enero de 1677), atendiendo a la importancia de poner en la plaza de Valdivia persona de toda confianza y brio, respecto de mantenerse recelo de enemigos, habiéndose confirmado con las noticias que entonces llegaron, de haber poblado en la cercanía del Estrecho...93, noticia

mente Mascardi, precisamente en estos años.

92 Declaraciones de los ingleses. Lima, 7 de marzo de 1675. BN, SM, MM, 235, Dcto. 2417

93 El virrey conde de Castellar. Lima, 21 de enero de 1675. AGI, Lima, 407, citado por Guarda, G. (1979). La sociedad en Chile austral antes de la colonización alemana, 1645-1845. Santiago, Chile: Andrés Bello, p. 140. 
que debe haber recibido del gobernador de Chiloé en diciembre de 1674. La relación entre Talcapillán y el fomento de las obras de defensa en Valdivia ya la hizo notar Vicuña Mackenna ${ }^{94}$, y puede verse en su nombramiento: habiéndose confirmado el haber poblado. La atención del virrey a Valdivia antes que a Chiloé o el Estrecho se explica por la imprecisa alerta de 1673 por el supuesto viaje al Mar del Sur de una flota comandada por Morgan para ir a infestar estos mares, pero que en Lima se hizo localizar en Valdivia, debido a la efectiva llegada de Narborough años antes, quien se había impuesto del precario estado de defensa de la plaza, por lo que se creía factible que alli quisieran volver. No es Talcapillán, ni Morgan, sino Narborough el que hace centrar la atención en Valdivia. En cambio, en Chiloé, a partir de Talcapillán, la atención no se puso ni en Valdivia ni en el estrecho de Magallanes, sino que en el territorio intermedio entre la península de Taitao y el Estrecho. Pero la alerta sobre Morgan solo fue eso, una alerta. Las expediciones salidas desde Chiloé no encontraron nada, aunque lo que buscaban no era a Morgan, sino colonias fundadas algunos años antes.

\section{EL MAPA DE NARBOROUGH, 1676}

a. Londres: el mapa

Después del desengaño de Talcapillán, ni en Chiloé, ni en Chile, ni en el virreinato se pensaba

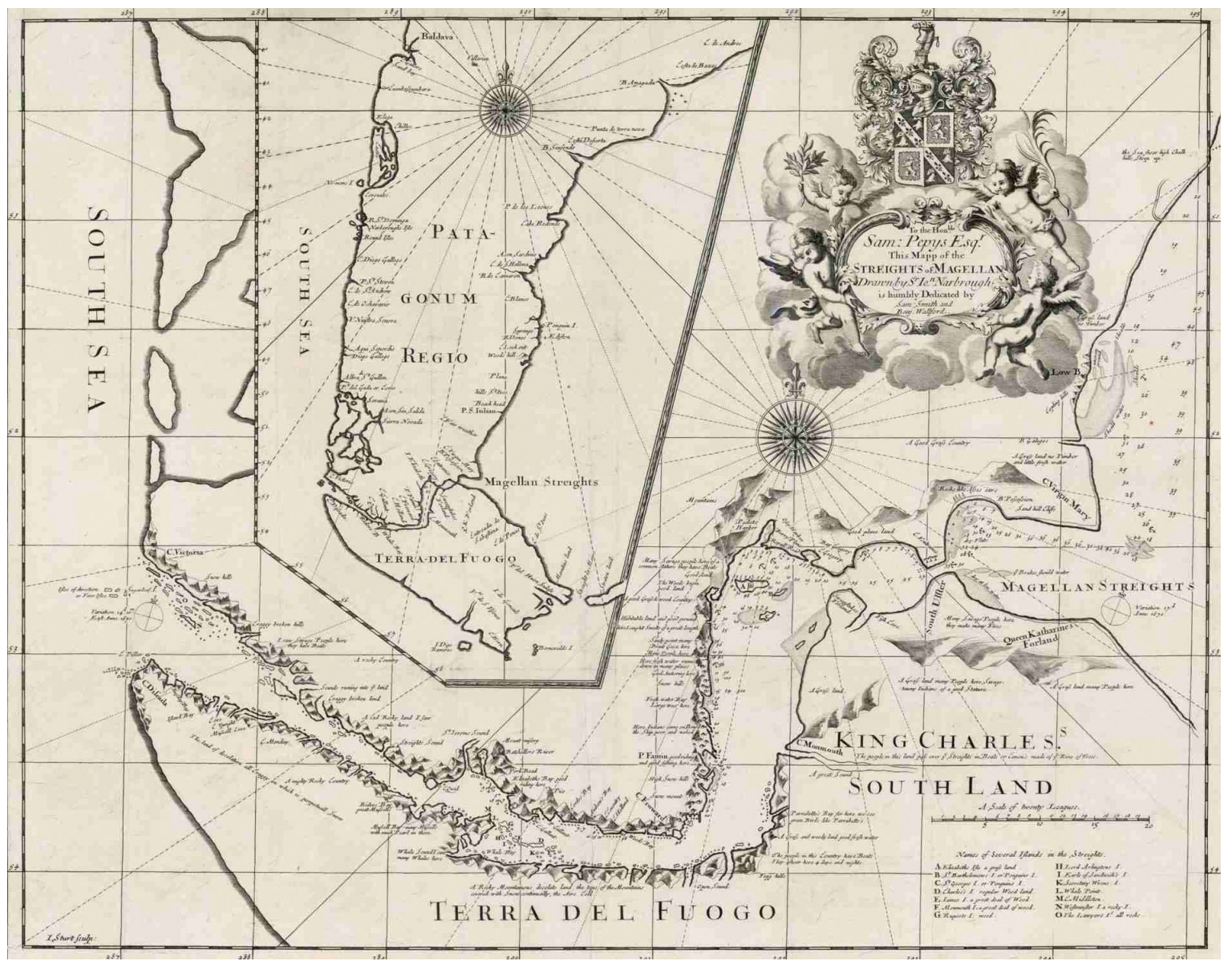

Fig. 3. John Narborough, 1694. To the Honble. Sam: Pepys Esqr. This Mapp of the Streights og Magellan Drawn by Sr. Ion. Narbrough is humbly Dedicated by Sam Smith and Benj: Wallford. 44,5 x 43,2 cms. Barry Lawrence Ruderman An que Maps Inc. https://www.raremaps.com/gallery/detail/23297/To_the_Honble_Sam_Pepys_Esqr_ This_Mapp_of_the_Streights_of_Magellan/Narborough.html 
ya que hubiese colonias. En España no se sabía nada aun de Talcapillán y los viajes consecuentes cuando en octubre de 1676 Madrid recibió del abad Maserati -Juan Domingo Maserati, representante de España en la corte de Lisboa (1673-1681)-, la noticia de haber un plan inglés para apoderarse del Estrecho. Adjuntaba un mapa detallado de él, que identificaba puertos y perfil de las costas ${ }^{95}$. El abad Maserati explicaba que, el estrecho que antes se tenía por innacesible e insuperable ahora le han facilitado. Además, informó el diplomático que los ingleses habían enviado familias a poblarle y que iban a erigir una fortaleza ${ }^{96}$. No sabemos el parecer del rey sobre esta noticia, sólo que el Consejo de Indias le informó ${ }^{97}$, ni tenemos la correspondencia que de seguro hubo con Chile, pero muy probablemente el gobernador de Chile dio cuenta de los tres viajes recientes. Eso si, ninguno de ellos había llegado a la boca del Estrecho. La información dada por el representante español en Portugal era la de Narborough difundida en Londres por Seller ${ }^{98}$.

\section{b. Madrid: ingleses en Tierra del Fuego, 1680}

En 1680 el procurador general de la Compañía de Jesús en Indias, Alonso de Pantoja, envió una carta a la corte, desde España también, respaldando una antigua petición de los jesuitas de Chile para la creación de un colegio en la ciudad de La Serena, norte de Chile. En su carta argumentó que Chile se hallaba tan pobre de sujetos de España y tan poco dilatados en ella, como se sabe, y que antes crecerá el número de los enemigos de esta Corona, de que Chile se halla tan amenazado, estando poblados los ingleses en Tierra del Fuego... Con esa colonia podrán los ingleses -prosigue Pantoja-, hacerse dueños de la Mar del Sur, y que no se podrá atajar que lo sea poblando de la banda de Chile

95 Como esta carta de Maserati la conocí por la copia hecha por Morla Vicuña, no es posible saber cuál mapa es al que se refiere, que obtuvo en Lisboa y que adjuntó en el original. En los años sucesivos hubo varias copias de los mapas del Estrecho hechos por Narborough, pero sólo se publicó uno en un libro, la primera vez en 1694. Adjunto uno de ellos.

96 Abad Maserati, 26 de octubre de 1676. ANH, MV, Vol. 20, pza. 14.

97 Consulta del Consejo de Indias a S.M., 8 de noviembre de 1676. AHN, MV, Vol. 20, pza. 15.

98 Sobre la correspondencia de Maserati, pero que no en la tierra que hasta ahora está inhabitada, por lo poco que se han extendido los españoles ni cuidado de indios o amistar aquellos naturales para que se hallen prontos a la defensa de los dominios de V.M. ${ }^{99}$. Se dice que se adjunta el mapa (Fig. 4) Con toda seguridad este mapa es uno existente en el Archivo General de Indias, datado como circa 1682, pero "suelto", no relacionado con la carta correspondiente. En ese mapa está escrito Población de ingleses aquí en esta tierra del fuego, en el sector oriental de la isla. ¿Porqué Pantoja en 1680 dio por cierta la sospecha de una colonia inglesa en el extremo sur americano, latente desde Morgan, 1673? ¿Será consecuencia de la reactivación del tema hecha por Maserati en 1676? ¿Cómo y porqué la sospecha de la colonia en el Estrecho se transformó en una en Tierra del Fuego?

Por el mapa el Consejo entendió que en la tierra que llaman del Fuego están poblados ingleses, de que hasta ahora no se ha tenido noticia ${ }^{100}$. El Consejo, entonces, acordó pedir informes a las autoridades de Chile sobre esta población [la inglesa] y de qué tiempo a esta parte se ha introducido, y en qué paraje, qué gente tendrá y cómo se sustentan, y si tienen sus habitadores algún trato y comercio, y con qué provincias, y siendo cierta esta noticia digan cómo se podrá desalojar a los ingleses de aquellas costas y Tierra del Fuego, y los medios con que se podrá conseguir con menos costa a la real hacienda ${ }^{101}$. Esto se hizo por real orden dada en 26 de febrero de 1681, enviada a Chile en junio del mismo año y recibida en abril de $1682^{102}$, documentos que demuestran que en la corte, al parecer, no se conocían los sucesos ocasionados por Talcapillán, episodio finalizado cinco años antes. Los informes, hechos en 1682 , hablan de los viajes de Gallardo y de Vea/Iriarte,

considera esta carta, véase a Cardim, P. (2005). Nem tudo se pode escrever. Correspondencia diplomática $e$ información 'política' en Portugal durante el siglo XVII. Cuadernos de Historia Moderna. Anejos, 4, 95-128.

99 El Consejo de Indias al rey. Madrid, 7 de febrero de 1681. BN, SM, MM, 387, pp. 82-86.

100 Idem.

101 El Consejo de Indias informa a SM, 3 de febrero de 1681. BN, SM, MM, 166, Dcto. 3383.

102 Real orden al presidente de Chile, de 26 de febrero de 1681. BN, SM, MM, 166, Dcto. 3385. 


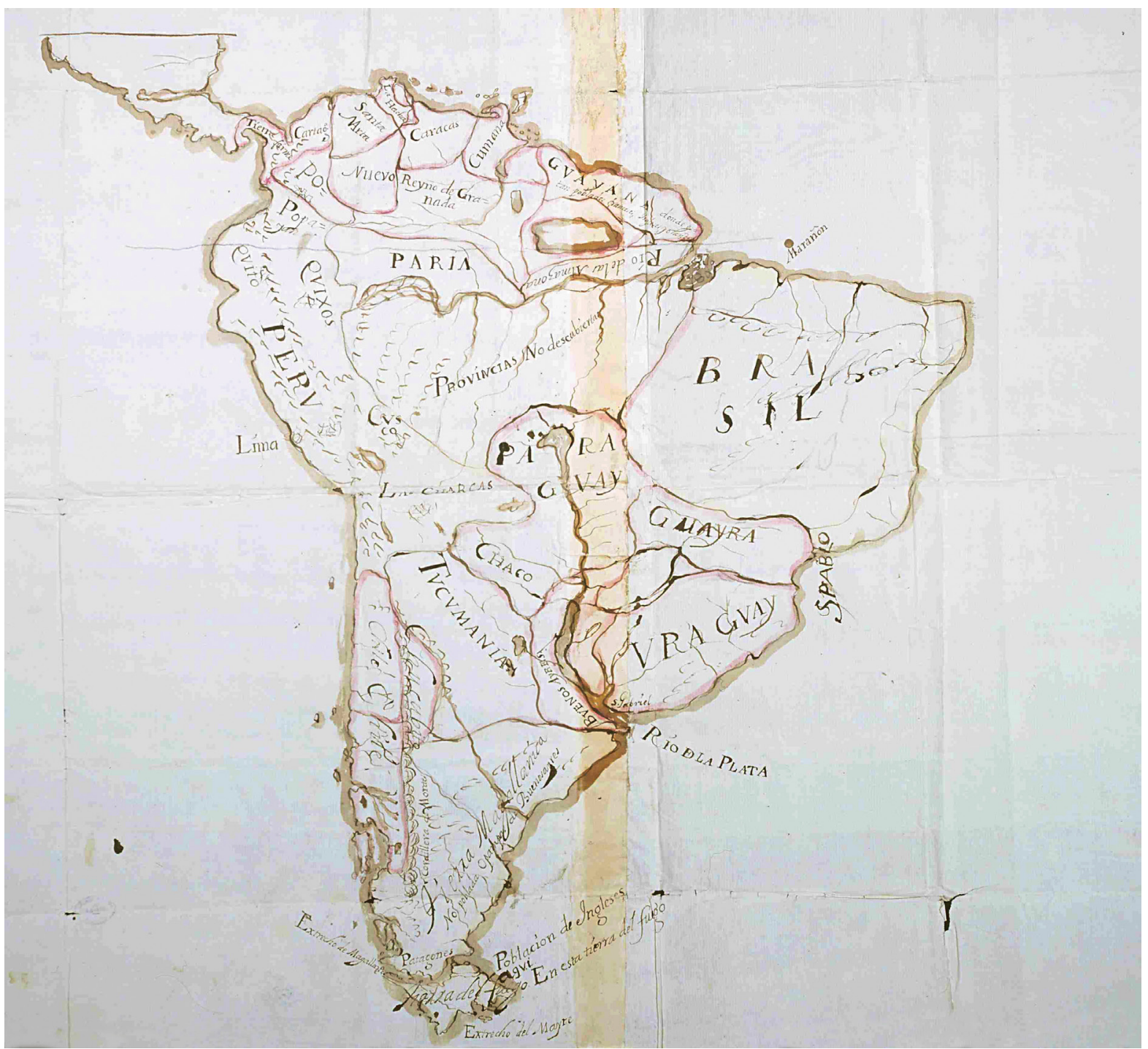

Fig. 4. Mapa de América del Sur con indicación de tierras habitadas por extranjeros, ca. 1682. AGI, Mapas y Planos, Perú-Chile, 176.

y dan por muy improbable que haya colonias inglesas en tan altas latitudes. Por ejemplo, fray Bernardo, obispo de Santiago, concluyó que se ha tenido por fabulosa la relación del indio, pues en tanto tiempo no ha resultado efecto alguno que la pudiese acreditar y esta población nunca se entendió que fuese en la Tierra del Fuego, que está descontinuada de la tierra firme de estas provincias y forma el Estrecho por donde se comunica esta Mar del Sur con la del norte. Y subiendo la tierra arriba de la provincia de Chiloé al Estrecho por esta costa del Mar del Sur es tanta la aspereza y frialdad que la hace estéril de todos mantenimientos y no se puede prestar cómoda habitación para nuevas colonias, y si alguna parte se hubiese de poblar de naciones extranjeras sería a la vuelta del Estrecho, en el Mar del Norte, en la distancia que hay entre el Estrecho al puerto de Buenos Aires, porque se entiende ser por aquella parte la tierra más fértil y templada, y en la que llaman del Fuego será mas dificultosa la población, porque estando a más grado de altura cerca del polo antártico se tiene por casi inhabitable, y últimamente como quiera no se ha entendido ni averiguado 
que haya población ${ }^{103}$.

La noticia de Pantoja y su mapa generaron órdenes de averiguar en el virreinato del Perú, lo que incluyó un nuevo interrogatorio en Lima a Carlos Enríquez ${ }^{104}$.

c. Chile: interés jesuita en el estrecho de Magallanes, 1681

Paralelo a esto, en junio de 1681 (antes de recibirse en Chile la orden de averiguar dada por el rey, como consecuencia del mapa de Pantoja) el jesuita Francisco Ferreira desde Chile pidió, en carta al rey, 24 misioneros para esta provincia, $e$ incluía entre las misiones a atender una que se haría en el estrecho de Magallanes ${ }^{105}$. Es decir, mientras en Madrid, primero, se creía que había ingleses en el área del Estrecho, por haberlo averiguado en Londres (o en Lisboa por Maserati); y luego en Tierra del Fuego, por afirmarlo una autoridad jesuita; en Chile se pensaba en el Estrecho (y no en Tierra del Fuego), pero para misionar.

Luego del desengaño de Talcapillán (1675); del mapa de Narborough (1671) e informe del abad Maserati, que lo retomó en 1676, sobre ingleses en el Estrecho; y del mapa del jesuita (1680), el peligro estaba en el Estrecho o Tierra del Fuego, y no en las costas pacíficas. Por lo tanto, se podía llegar por tierra firme por Nahuelhuapi. Por lo tanto, la atención de la Corona, al menos teórica, en informarse acerca del Estrecho es coincidente con el interés jesuita de proyectarse a él. Pero fue solo coincidencia, porque tienen un distinto origen: Narborough, que es de origen imperial; y Mascardi, local.

Esta petición misional fue presentada

103 Fray Bernardo, obispo de Santiago, al rey. Santiago, 30 de abril de 1682. BN. SM, MM, 166, Dcto. 3386.

104 Lima, 5 de mayo de 1682. BN, SN, MM, 166, Dcto. 3412. Luego de esta declaración se le sentenció al garrote. BN, SM, MM, 166, Dcto. 3423.

105 El jesuita Francisco Ferreira, Santiago, 8 de junio de 1681. ANH, MV, Vol. 20, pza. 17.

106 Informe de Juan Nepomuceno Walter. Santiago, 9 de enero de 1764. AGI, Chile, 240.

107 Los jesuitas habían intentando evangelizar a los indígenas bordemarinos del sur de Chiloé, desde 1611 hasta la década de 1630. En esos años el provincial jesuita del Perú afirma que si no se da limosna para la misión de Chonos se perdiera la esperanza que hay de que los padres de la Compañía han de ir pasando adelante convirtiendo también, más tarde, en 1764, por el procurador de los jesuitas en Chile, Juan Nepomuceno Walter ${ }^{106}$. Tanto la propuesta de 1681 , de salir los religiosos desde la misión de Nahuelhuapi al Estrecho por tierra firme; como la de 1764, de salir desde una que se quería fundar en la isla Cailín, situada en el mar interior de Chiloé, por la costa ${ }^{107}$, son fruto del ideal misionero jesuita, y la Corona no pudo más que consentir. Ordenó la refundación de Nahuelhuapi en 1703 (aunque al menos desde 1684 se habla de que ya existe, de facto, atendida desde Chiloé) y la de Cailín en 1764, pero ninguna dio frutos: por la hostilidad de los indígenas los misioneros solo pudieron permanecer algunos años en la misión de Nahuelhuapi ${ }^{108}$, y desde Cailín apenas hicieron dos viajes (los del padre José García) al sur del golfo de Penas, sin llegar al Estrecho. Luego vino la expulsión de la orden. Entonces, vemos cómo las pretensiones geopolíticas de Inglaterra no provocaron acciones en el Estrecho, sino que fueron los objetivos misionales, dejando en manos de los jesuitas una teórica defensa sobre la base de la fidelidad hacia el rey de los patagones y grupos canoeros australes de las inmediaciones de Magallanes ${ }^{109}$.

d. Madrid: ingleses en las costas magallánicas, 1682 y 1690

En 1682 los ingleses Bartolomé Sharp y Basil Ringrose, al regreso de sus correrías por las costas del norte de Chile y sur del Perú recalaron en una isla que se llamó Duque de York, contigua por el sur a la isla Madre de $D_{i o s}{ }^{110}$. Una vez en Inglaterra con rapidez se

las naciones que hay en islas y tierra firme hasta el mismo estrecho de Magallanes. Carta del virrey conde de Chinchon, sin fecha, pero corresponde a las cartas y expedientes del año 1634. En esa carta el virrey informa sobre los sínodos de las misiones jesuitas y remite la relación del provincial jesuita, que habla de Chonos. ANH, VG, Vol. 20.

108 Urbina, M. X. (2008). La frustrada misión estratégica de Nahuelhuapi, un punto en la inmensidad de la Patagonia. Magallania, 36 (1), 5-30.

109 Véase a Casanueva, F. (1982). La evangelización periférica en el Reino de Chile. Nueva Historia, 5, 5-30.

110 Martinic, M. (2007). Los británicos en la Región Magallánica, Valparaíso, Chile: Editorial Puntángeles, $\mathrm{p}$. 29. 
difundieron estas noticias, planos y mapas ${ }^{111}$. Martinic afirma que es producto de tales noticias, y de las consecuencias inmediatas de Narborough (búsquedas desde Chiloé), que Francisco de Seixas y Lovera en 1690 dirigió a la corte su Descripción Geographica y Derrotero de la Región Austral Magallánica, obra en la que prevenía a la corona sobre el riesgo de desproteger esa región, y también el mapa, que analiza en el artículo recién citado.

\section{e. Chiloé: despoblar la isla, 1684}

Por último, es interesante observar que un informe de Lima de 1684, sobre la conveniencia de mantener la proyectada nueva misión de Nahuelhuapi desde Chiloé afirma algo de lo que no tenemos otra noticia: ofrece la dificultad del parecer de algunos para que se despoblase Chiloé y se retirase toda aquella gente a Chile, porque la esterilidad y despoblación defendiese aquella tierra a causa de no lo estar con los españoles que hay en ella ${ }^{112}$ Pareciera ser que esta idea de presentar a los ingleses un Chiloé despoblado no tiene su origen en el querer ofrecer con ello defensa, sino que es aprovechar la coyuntura para abandonar la vida aislada y la pobreza de la provincia (no estaba permitido despoblarla), y trasladarse a Chile ${ }^{113}$. Lo propuso también en 1681 un franciscano: que se trasladase a los habitantes de Chiloé a La Serena y poblasen también la antigua ciudad de La Imperial, para ofrecer a los ingleses una isla despoblada ${ }^{114}$. Nunca se pensó en fortificar la isla (sino hasta la segunda mitad del siglo XVIII), como si se pensó en Valdivia, luego de la ocupación holandesa de 1643. Probablemente despoblar Chiloé era un sentir de los españoles de Castro en la misma fecha, que vio la ocasión en esta coyuntura, por la repentina atención prestada a la isla. Esta reacción de algunos es otro ejemplo, junto con la petición de las autoridades de mayores recursos para la defensa, de cómo hay una valoración local del problema imperial.

111 Martinic, M. (1997). Rarezas cartográficas. I. Las cuatro versiones del mapa de Chile del padre Alonso de Ovalle. II. El curioso mapa de la región magallánica de Francisco de Seixas y Lovera (1690). Boletín de la Academia Chilena de la Historia, 107, 385-400.

112 Informe fechado en Lima, 24 de enero de 1684. ANH,

\section{CONCLUSIONES}

La presencia de Narborough y Enríquez en Valdivia en diciembre de 1670, y con ello la prueba fáctica del antiguo temor al holandés e inglés, provocó reacciones imperiales, regionales y locales hacia las costas australes. Estas fueron la activación de las sospechas de establecimientos ingleses en lugares itinerantes del extremo Pacífico Sur; las expediciones de la provincia, del reino y del virreinato en su búsqueda; la ocasión de un indio no españolizado de interiorizarse en la comprensión española de las costas y archipiélagos; las opiniones y planes ingleses sobre sus intereses en el territorio; y los proyectos jesuitas de establecer una misión en el confín del continente.

Las noticias recibidas en más de una ocasión por la corte desde su red de espionaje en Londres (presencia real de Narborough en 1670-71; presencia imaginada de Morgan en 1673; mapa del estrecho de Narborough de 1676 y supuesta colonia en él; y mapa jesuita de 1680) hicieron que en este período se prestara atención al estrecho de Magallanes, por noticias externas o imperiales. Pero estas coyunturas generaron otros hechos (Talcapillán, 1674), de carácter local, que prestaron atención a las costas que conducían al Estrecho.

Por otro lado, la efectiva presencia de ingleses (solo Narborough, frente a Valdivia, en 1670), no provocó alarma en Chile sobre un posible interés en Magallanes y el confín austral, porque en Chile solo importó la seguridad de Valdivia. En cambio, la creencia local, en Chiloé y Lima, sobre las dos colonias inglesas reveladas por Talcapillán en 1674, sí que ocasionaron dos grandes expediciones de reconocimiento. $Y$ aunque no se encontró nada, la creencia en los moroguincas quedó latente y se reactivó en el siglo siguiente. Pero es, por lo tanto, en 1674, una noticia llegada desde la corte de haber ingleses en el extremo sur, la que da origen al relato de Talcapillán, y que, a su vez, permite que lo que dice este chono resulte verosímil al gobernador de Chiloé y el virrey del

MV, Vol. 20, pza. 18.

113 Sobre esto véase a Urbina, R. (1983). La periferia meridional indiana. Chiloé en el siglo XVIII. Valparaíso, Chile: Ediciones Universitarias de Valparaíso.

114 Fechada el 12 de septiembre de 1681. AGI, Chile, 24. Referencia tomada de Gil 1989, op. cit., p. 304. 
Perú. Así, circula y se entrecruza la información.

La atención en el Estrecho y costa pacífica austral hizo que desde el virreinato y desde la corte, por primera vez, se le diera algún valor estratégico a la postergada y pobre provincia insular de Chiloé, que aprovechó la coyuntura para pedir liberarse del encierro insular, despoblando la isla. Pero también, la proyectada misión de Nahuelhuapi durante y después de Mascardi era del general interés insular, porque permitiría, por esa vía, salir del encierro comunicando con Chile a través de las pampas, o descubrir a los Césares, por el sur.

La Corona y los jesuitas, por lo tanto, tienen intereses distintos: uno es estratégico y fruto de una necesidad externa (expulsar al inglés o impedir que se asiente), otro es misional y fruto de una necesidad interna (conversión de gentiles remotos y desconocidos). Si coinciden en los mismos años es porque el temor al inglés no sólo fue producto de flotas que se sabía que zarparían hacia estas costas, sino porque efectivamente habían llegado (primero Narborough al Estrecho y Valdivia; e ingleses que estarían poblando Tierra del Fuego, según un mapa), y estaba en consonancia con las intenciones jesuitas de ganarles los patagones a los ingleses. Esto no podía sino ser atractivo para la Corona, porque como hizo notar Fernando Casanueva, las misiones jesuitas y franciscanas fueron vistas como un medio para el control del territorio y sus pobladores hasta entonces solo nominalmente incorporados.

La de Narborough fue la expedición que efectivamente ocurrió. En esa ocasión el inglés llegó, y sin hacer daño, se fue. Todo lo demás fueron solo noticias adquiridas en España sobre expediciones planeadas en Londres; informaciones llegadas desde las islas Canarias, Madeira, el Caribe, o Brasil, sobre expediciones inglesas que, diciendo que continuaban su viaje hacia las Indias Orientales, trascendía que iban a los puertos del océano Pacífico; velas sospechosas avistadas en Valdivia o Chiloé, que se suponían expediciones inglesas; o noticias de posibles asentamientos ingleses entre el sur de Chiloé y el confín de la tierra, nacidas de lo que podría haber en el islario austral de esa provincia. Sobre estas noticias, papeles o avisos es interesante hacer un estudio que las vincule entre sí, a lo largo de los años; las vincule también con las acciones locales; y lo haga además con otros ataques, reales o imaginarios, de ingleses en América. La comprensión de estas relaciones sincrónicas y diacrónicas son una manera de estudiar, como lo es asimismo la circulación de la información en el imperio español, en este caso, el extremo sur de Chile; y la manera en que los distintos interlocutores representan (interpretan) el territorio. La valoración tácita y expresa de las costas entre el estrecho de Magallanes y Valdivia por parte de Inglaterra impulsó una nueva valoración o representación española de tales territorios. Esta valoración fue distinta en el almirantazgo inglés, en la corte española, en el virreinato del Perú y en la gobernación insular de Chiloé. Eso es lo que he pretendido ofrecer al estudiar esta coyuntura geopolítica ocurrida en un lugar remoto de los centros de interés indianos, que permite al historiador aproximarse a maneras diferentes de representar y comprender los territorios en el siglo XVII.

\section{FUENTES DE CONSULTA}

a) Manuscritos

- The British Library, Londres, Add. Ms. 21.539, Spanish American Papers, Melfort Papers.

Carta de Carlos Enríquez al virrey del Perú, Valdivia, 27 de enero de 1671.

El capitán Bartolomé Iñiguez de Ciriano, escribano mayor de la Real Hacienda, minas y registros. Valparaíso, 6 de enero de 1671.

El virrey del Perú, conde de Lemos, al presidente de Panamá, Juan Pérez de Guzmán. Lima, 24 de enero de 1671.

- The National Archives, Londres, State Papers 94: State Papers Foreign, Spain, 1577-1780.

El marqués del Fresno a la reina. Londres, 28 de marzo de 1672.

- Archivo General de Indias, Sevilla

Fondo Gobierno, Audiencia de Chile:

Vol. 7: El gobernador de Chiloé. Chacao, 29 de octubre de 1674 .

Vol. 23, R.3, N.83: El virrey del Perú al rey, Lima, 28 de abril de 1675 .

Vol. 240: Informe de Juan Nepomuceno Walter. Santiago, 9 de enero de 1764.

Fondo Gobierno, Audiencia de Lima:

Vol. 72: El virrey conde de Lemos. Lima, de 14 de febrero de 
1671.

Vol. 407: El virrey conde de Castellar. Lima, 21 de enero de 1675.

Fondo Mapas y Planos, Buenos Aires:

Vol. 226: Anónimo, 1671. "Tabla del procedimiento del viaje de una fragata y un patache ingleses al estrecho de Magallanes".

- Archivo del Museo Naval de Madrid

Iriarte, Pascual de, "Relación diaria del viaje marítimo y descubrimientos de las costas del sur que hizo por orden el excelentísimo señor conde de Castellar, marqués de Malagón, virrey, gobernador y capitán de estos reinos del Perú, Tierra Firme y Chile, el capitán de mar y guerra Pascual de Iriarte, en el navío Nuestra Señora del Rosario, que continuó en el de la Santísima Trinidad, desde la provincia de Chiloé hasta el estrecho de Magallanes y Tierra del Fuego, por el recelo de las poblaciones que se suponían hechas por el inglés en aquellas costas, siendo piloto mayor el capitán Guillermo Bautista de Echavarría. Año de 1675". Ms. 191, fjs. 39-69.

Vea, Antonio de, "Relación diaria del viaje que se ha hecho a las costas del estrecho de Magallanes, en el recelo de enemigos de Europa, por Don Antonio de Vea", Año de 1675. Ms. 199, fjs. 576-619.

- Archivo Nacional Histórico, Santiago de Chile

Fondo Capitanía General, Vol. 715:

Cédula del rey al presidente de la Audiencia de Chile, Madrid, 13 de septiembre de 1660 .

Cédula del rey al presidente de la Audiencia de Chile, Madrid, 25 de septiembre de 1660.

El conde de Molina a la reina. Londres, 10 de julio de 1671.

Cédula de la reina al presidente de Chile, Madrid, 30 de diciembre de 1671 .

Fondo Morla Vicuña:

"Relación de cartas, decretos y consultas sobre el peligro inglés en América Meridional". Vol. 5, pieza 48.

Abad Maserati, 26 de octubre de 1676. Vol. 20, pza. 14.

Consulta del Consejo de Indias a S.M., 8 de noviembre de 1676. Vol. 20, pza. 15.

El jesuita Francisco Ferreira, Santiago, 8 de junio de 1681. Vol. 20, pza. 17.

Informe fechado en Lima, 24 de enero de 1684. Vol. 20, pza. 18.

Fondo Vidal Gormaz:

Carta del virrey conde de Chinchon. Vol. 20.
El conde de Molina a la reina. Londres, 24 de julio de 1671. ANH, Vidal Gormaz, Vol. 11, pza. 32.

- Biblioteca Nacional, Santiago de Chile, Sala Medina, Manuscritos Medina:

Declaraciones ante Francisco de Cárdenas, fiscal de la Audiencia. Valparaíso, 12 de marzo de 1671. Tomo 161, Dcto. 3221.

El licenciado Don Pedro García de Ovalle al Sr. Diego Sarmiento de Valladares. Lima, 10 de mayo de 1671. Tomo 161, Dcto. 3227.

El conde de Molina a la reina, Londres, 14 de julio de 1671. Tomo 161, Dcto. 3229.

Consulta del consejo de Estado a la reina, 21 de octubre de 1671. Tomo 161, Dcto. 3241.

"Relación del socorro que el excelentísimo señor conde de Lemos, virrey del Perú, envió a tierra firme para desalojar de Panamá al pirata inglés con otros sucesos de aquel reino". Tomo 161, Dcto. 3249.

El gobernador de Chile a la reina. Santiago, 27 de diciembre de 1673. Tomo 163, Dcto. 3311.

El Consejo de Indias informa a SM, 3 de febrero de 1681. Tomo 166, Dcto. 3383.

Real orden al presidente de Chile, de 26 de febrero de 1681. Tomo 166, Dcto. 3385.

Fray Bernardo, obispo de Santiago, al rey. Santiago, 30 de abril de 1682. Tomo 166, Dcto. 3386.

Declaración de Alonso de Figueroa y Córdoba, Santiago, 2 de junio de 1681. Tomo 166, Dcto. 3398.

Declaraciones de los prisioneros ingleses. Lima, 5 de mayo de 1682. Tomo 166, Dcto. 3412.

Sentencia a Carlos Enríquez. Tomo 166, Dcto. 3423.

Declaraciones a los ingleses. Lima, 7 de marzo de 1675 . Tomo 235, Dcto. 2417.

El Consejo de Indias al rey. Madrid, 7 de febrero de 1681. Tomo 387.

b) Impresos

VV.AA. (1694). An account of several late voyages and discoveries to the south and north. Towards the streights of Magellan, the South Seas, the vast tracts of land beyond Hollandia Nova, also towards Nova Zembla, Greenland or Engrondland, by Sir John Narborough, capitan Jasmen Tasman, capitan John Wood, and Frederick Marten of Hamburgh. Londres, Inglaterra: Printed for Sam. Smith and Benj. Walford, printers to the Royal Society, at the Prince's Arms, in S. Paul's Churchyard. 
Byron, J., Bulkeley, J., Cummins, J., Morris, I., \& Campbell, A. (2012). Cuatro relatos para un naufragio. Los protagonistas de la Wager en el golfo de Penas en 1741. Santiago, Chile: Septiembre Ediciones.

Gallardo, B. (1886). Relación del sargento mayor Don Bartolomé Gallardo hecha en Lima de orden de V. E. sobre el viaje que hizo en reconocimiento a las poblaciones de los ingleses con todo lo sucedido en él y paraje donde llegó, (1674-1675). Anuario Hidrográfico de la Marina de Chile, 11, 525-537.

Seller, J. (1670?). Atlas Maritimus or A book of charts describeing the sea coasts, capes, headlands, sands, shoals rocks and dangers the bayes roads, harbors, rivers and ports, in the most of the knowne parts of the world.... Londres, Inglaterra.

c) Publicados

Albi, J. (1987). La defensa de las Indias (1764-1799). Madrid, España: Instituto de Cooperación Americana.

Barros, J. (1988). La expedición de Narborough a Chile: nuevos antecedentes. Anales del Instituto de la Patagonia, Serie Ciencias Sociales, 18, 35-59.

Barros. D. (1932). Historia aeneral de Chile. Santiaqo. Chile: Nascimento. Tomo V.

Böhm, G. (1980). Simon de Casseres y su plan de conquista de Chile: antecedentes históricos. Ibero-Amerikanisches Archiv, Neue Floge, 6(1), 117-147.

Bradley, P. (1986). Narborough's Don Carlos. The Mariner's Mirror, 72(4), 465-475.

Cardim, P. (2005). Nem tudo se pode escrever. Correspondencia diplomática e información 'política' en Portugal durante el siglo XVII. Cuadernos de Historia Moderna. Anejos, 4, 95-128.

Casanueva, F. (1982). La evangelización periférica en el Reino de Chile. Nueva Historia, 5, 5-30.

Dyer, F. (1931). The life of admiral Sir John Narbrough. "The great commander and able seaman". London, England: P. Allan.

Gil, J. (1989). Mitos y utopías del Descubrimiento, Tomo 2, El Pacífico. Madrid, España: Alianza.

Guarda, G. (1979). La sociedad en Chile austral antes de la colonización alemana, 1645-1845. Santiago, Chile: Andrés Bello.

Guarda, G. (1981). Atlas cartográfico del Reino de Chile. Siglos XVII-XIX. Santiago, Chile: Instituto Geográfico Militar.

Guarda, G. (1990). Flandes Indiano. Las fortificaciones del Reino de Chile, 1541-1826. Santiago, Chile: Universidad Católica de Chile.

Guarda, G. (2001). Nueva Historia de Valdivia. Santiago, Chile: Universidad Católica de Chile.

Guarda, G., Moreno, R. (2008). Monumenta Cartographica Chiloensia. Misión, territorio y defensa, 1596-1826. Santiago, Chile: Pehuen.

León, L. (2001). Indios, piratas y corsarios en las costas de Araucanía y Patagonia, 1557-1790. Boletín de Historia y Geografía, 15, 117-151.

Lira, N., \& Legoupil, D. (2014). Navegantes del sur y las regiones australes. En C. Aldunate (Ed.), Mar de Chile (pp. 102-143). Santiago, Chile: Ediciones del Museo Chileno de Arte Precolombino.

Lohmann, G. (1946). El conde de Lemos. Madrid, España: Publicaciones de la Escuela de Estudios Hispanoamericanos de la Universidad de Sevilla.

Martinic, M. (1977). Historia del estrecho de Magallanes. Santiago, Chile: Andrés Bello.

Martinic, M. (1992). Historia de la Región Magallánica. 2 Vols. Punta Arenas, Chile: Universidad de Magallanes.

Martinic, M. (1997). Rarezas cartográficas. I. Las cuatro versiones del mapa de Chile del padre Alonso de Ovalle. II. El curioso mapa de la región magallánica de Francisco de Seixas y Lovera (1690). Boletín de la Academia Chilena de la Historia, 107, 385-400.

Martinic, M. (2007). Los británicos en la Región Magallánica, Valparaíso, Chile: Editorial Puntángeles.

Martinic, M., \& Moore, D. (1982). Las exploraciones inglesas en el estrecho de Magallanes 1670-1671. El mapa manuscrito de John Narborough. Anales del Instituto de la Patagonia, Serie Ciencias Humanas, 13, 7-20.

Morla, C. (1903). Estudios histórico sobre el descubrimiento y conquista de la Patagonia y de la Tierra del Fuego. Leipizg, Alemania: F. A. Brockhaus.

Sánchez, J. (1999). Las relaciones internacionales de la monarquía hispánica durante la regencia de doña Mariana de Austria. Studia Historica. Historia Moderna, 20, 137-172.

Stewart, H. (2000). Del Mar del Norte al Mar del Sur. Navegantes británicos y holandeses en el Pacífico suroriental, 1570-1807. Valparaíso, Chile: Universidad de Playa Ancha.

Urbina, R. (1983). La periferia meridional indiana. Chiloé en el siglo XVIII. Valparaíso, Chile: Ediciones Universitarias de Valparaíso.

Urbina, M. X. (2008). La frustrada misión estratégica de Nahuelhuapi, un punto en la inmensidad de la Patagonia. Magallania, 36(1), 5-30. 
Urbina, M. X. (2011). La proyección de Chiloé hacia la Patagonia Insular en el siglo XVIII. Anuario de Estudios Americanos, 68(2), 599-622.

Urbina, M. X. (2013). Expediciones a las costas de la Patagonia occidental en el período colonial. Magallania, 41(2), 51-84.

Urbina, M. X. (2014). El frustrado fuerte de Tenquehuén en el archipiélago de los Chonos, 1750: dimensión chilota de un conflicto hispano-británico. Historia, 47(1), 133155.

Urbina, M. X. (2015). El naufragio de la Wager en el Pacífico austral y el conflicto del hierro en Chiloé. En R. Sagredo y R. Moreno (Eds.), El Mar de Sur en la Historia. Ciencia, expansión, representación y poder en el Pacífico (pp. 239-278). Santiago, Chile: Centro de Investigaciones Diego Barros Arana, Dirección de Bibliotecas, Archivos y Museos, y Universidad Adolfo Ibáñez.

Urbina, M. X. (2016). Interacciones entre españoles de Chiloé y chonos en los siglos XVII y XVIII: Pedro y Francisco Delco, Ignacio y Cristóbal Talcapillán, y Martín Olleta. Chungara, 48(1) 10-114.

Urbina, M. X. (2016). Traslados de indígenas de la Patagonia occidental insular a Chiloé en los siglos XVI, XVII y XVIII. En J. Valenzuela (Ed.), América en diásporas: esclavitudes y migraciones forzadas (siglos XVI-XIX). Santiago, Chile, Pontificia Universidad Católica de Chile/RiL editores (en prensa).

Urbina, M. X. (2015). El chono Cristóbal Talcapillán y su información sobre colonias inglesas en la Patagonia Insular, 1674. Boletín de la Academia de Historia Naval y Marítima de Chile, 19, 27-44.

Vázquez de Acuña, I. (1992). Las incursiones corsarias holandesas en Chiloé: Simón de Cordes (1600) y Enrique Brouwer (1643). Santiago, Chile: Universitaria.

Vázquez de Acuña, I. (1993). La jurisdicción de Chiloé (siglos XVI al XX). Su extensión, exploración y dominio. Boletín de la Academia Chilena de la Historia, 103, 111-119.

Vázquez de Acuña, I. (2004). Historia naval del reino de Chile, 1520-1826. Valparaíso, Chile: Compañía Sudamericana de Vapores.

Vicuña, B. (1869). Historia de Valparaíso, crónica política, comercial y pintoresca de su ciudad y de su puerto, desde su descubrimiento hasta nuestros días, 15361868. Valparaíso, Chile: Imprenta de Albion de Cox y Taylor.

Villalobos, S. (1999). Historia del pueblo chileno. Santiago, Chile: Universitaria.

Wallis, H. (1965). English Enterprise in the region of the Strait of Magellan. En J. Parker (Ed.), Merchants \& Scholars. Essays in the history of exploration and trade (pp. 195-220). Minnesota, Estados Unidos de América: University of Minnesota.

Williams, G. (1973). "The inexhaustible fountain of gold": English proyects and ventures in the South Seas, 16701750. En J. Flint y Williams, G. (Eds.), Perspectives of Empire (pp. 27-53). London, England: Longman Group Limited.

Williams, G. (2002). El mejor botín de todos los océanos. La trágica captura de un galeón español en el siglo XVIII. Madrid, España: Turner Publicaciones.

Zuleta, J. (2013). La fortificación del estrecho de Magallanes: un proyecto al servicio de la imagen de la monarquía. Revista Complutense de Historia de América, 39, 153-176. 